\title{
Laboratory micro-seismic signature of shear faulting and fault slip in shale
}

\author{
J. Sarout ${ }^{\mathrm{a}}$, Y. Le Gonidec ${ }^{\mathrm{b}}$, A. Ougier-Simonin ${ }^{\mathrm{c}}$, A. Schubnel ${ }^{\mathrm{d}}$, \\ Y. Guéguen ${ }^{\mathrm{d}}$, and D.N. Dewhurst ${ }^{\mathrm{a}}$ \\ ${ }^{a}$ CSIRO Energy, Perth, Australia \\ ${ }^{b}$ Géosciences Rennes - CNRS/INSU UMR6118, Rennes, France \\ ${ }^{c}$ British Geological Survey, Engineering Geology, Keyworth, UK \\ ${ }^{d}$ Ecole Normale Supérieure, CNRS-UMR 8538, Laboratoire de Géologie, Paris, France
}

\begin{abstract}
This article reports the results of a triaxial deformation experiment conducted on a transversely isotropic shale specimen. This specimen was instrumented with ultrasonic transducers to monitor the evolution of the microseismic activity induced by shear faulting (triaxial failure) and subsequent fault slip at two different rates. The strain data demonstrate the anisotropy of the mechanical (quasi-static) compliance of the shale; the $\mathrm{P}$-wave velocity data demonstrate the the anisotropy of the elastic (dynamic) compliance of the shale. The spatio-temporal evolution of the micro-seismic activity suggests the development of two distinct but overlapping shear faults, a feature similar to relay ramps observed in large-scale structural geology. The shear faulting of the shale specimen appears quasi-aseismic, at least in the $0.5 \mathrm{MHz}$ range of sensitivity of the ultrasonic transducers used in the experiment. Concomitantly, the rate of micro-seismic activity is strongly correlated with the imposed slip rate and the evolution of the axial stress. The moment
\end{abstract}

Email address: joel.sarout@csiro.au (J. Sarout) 
tensor inversion of the focal mechanism of the high quality micro-seismic events recorded suggests a transition form non-shear dominated to sheardominated micro-seismic activity when the rock evolves from initial failure to larger and faster slip along the fault. The frictional behaviour of the shear faults highlights the possible interactions between small asperities and slow slip of a velocity-strengthening fault, which could be considered as a realistic experimental analogue of natural observations of non-volcanic tremors and (very) low-frequency earthquakes triggered by slow slip events.

Keywords: Shale, P-wave velocity, Anisotropy, Micro-seismicity, Focal mechanism, Shear faulting, Fault slip, Friction 
1

2

3

4

5

6

7

\section{Introduction}

Changes in the stress state can induce brittle damage (micro-fracturing) in rocks that can radiate mechanical energy in the form of Micro-Seismic (MS) activity, also called acoustic emissions [28, 31, 32]. Accumulation of damage can ultimately lead to mechanical failure of the rock. Among the various rock failure mechanisms listed in the literature, we focus here on brittle faulting pertaining to numerous geological settings observable during the deformation of rocks originating from the Earth's upper crust.

It is generally accepted that for a given material, MS activity is prominently observed during deformation under the following conditions: (i) relatively low normal stresses; (ii) relatively high shear stresses; and/or (iii) relatively high stress loading rates, e.g., $[1,51]$. In the past, most research efforts published in the literature involving micro-seismic monitoring of deformation processes in the laboratory have focused either on:

- crystalline rocks in relation to earthquake/fault mechanics, geotechnical or geothermal applications, e.g., [6, 26, 29, 33]; or

- conventional reservoir rocks in relation to oil and gas exploration, production and monitoring (reservoir integrity, compartmentalisation, injectioninduced fracture/fault reactivation...), e.g., in sandstones $[7,8,9,15,17,45]$; or to a lesser extent in porous carbonate rocks [16].

At the field scale, several studies on the monitoring of MS activity in granites and carbonates have been published. These include the monitoring of: thermally-induced MS activity potentially associated with radioactive waste disposal in boreholes drilled in a tunnel's floor at Äspö's Hard Rock Laboratory in Sweden [37], in the Excavation Damage Zone (EDZ) in the Un- 
derground Research Laboratory in a granitic rock mass in Canada $[53,54]$ and injection-induced MS activity in a limestone formation in the Laboratoire Souterrain à Bas Bruit in France [18]. Fewer field-scale studies on the MS activity induced by faulting or fault slip in shale formations have been published. A recent study demonstrated the feasibility of monitoring the time evolution of MS activity associated with the EDZ in the Opalinus Clay formation at the Mont-Terri Underground Research Laboratory in Switzerland [27]. The MS activity associated with fluid injection in the Colorado Shale formation was successfully monitored by [46]. In contrast, the monitoring of the spatial extent of anthropogenic hydraulic fractures in stimulated oil/gas reservoirs have been an active field of research since the 1980's, strongly supported by industry funding, especially in the recent years with the advent and development of commercially-viable unconventional reservoirs such as gas shales, e.g., [49].

At the laboratory scale, experiments have been reported on shales uniaxially deformed at room conditions under large loading rates (see [2] and references therein). However, no determination of spatial locations or focal mechanisms of the recorded MS events (MSEs) was carried out. In addition, the assessment of the frictional behaviour of the generated fractures (postfailure behaviour) and the characterisation of its MS response to slip is not practically feasible under such experimental conditions due to the unstable nature of the induced brittle failure. MS activity and location in shale samples containing quartz veins have been reported by [30]. In this particular case, and as expected, the MS activity seemed to coincide with the location of quartz veins favorably oriented with respect to the maximum principal 
compressive stress.

To our knowledge, no data on spatio-temporal localisation and focal mechanism estimation of MS activity have been reported on deforming clayrich rocks such as conventional reservoir-sealing shales. Under triaxial deformation at realistic subsurface stress conditions, the shale specimens fail in shear, leading to the formation of a shear fracture. The first questions that arise then for these rocks are the following: (i) can we expect precursory micro-seismic activity prior to the macroscopic faulting? (ii) Would the slip on the newly generated fault induce any micro-seismic activity? (iii) How would the signature of the MS activity be affected by the deformation rate?

Due to their fine-grained nature, it is generally thought that clays act as a lubricant in frictional geological environments, e.g., [36]. Also, the brittleness of clay behaviour is known to be controlled by their degree of hydration (the more hydrated, the less brittle), their mineral composition, and the imposed deformation rate (higher rates induce a more brittle response). The lack of published experimental studies on the MS activity of shales subjected to stress conditions typical of the upper crust can probably be explained by the inherent complexity of shales and the associated difficulty in conducting laboratory deformation experiments on them under well-controlled conditions. In addition, there is considerable technical complexity in conducting and processing laboratory experiments aimed at monitoring and locating with high accuracy the MS activity induced by deforming relatively small specimens. In this regard, the difficulty in locating the MS activity is exacerbated by the directional dependency (anisotropy) of wave propagation in shales, e.g., $[11,13,24,39,40,48]$. 
In this paper, the results and analysis of a laboratory deformation experiment in a shale specimen are reported. The specimen was triaxially deformed to beyond the failure point under realistic subsurface stress conditions while associated MS activity was recorded. The aim was to analyse the contrast in the MS signature of shear faulting and subsequent fault slip as well as the effect of the deformation rate on the fault's micro-seismic and frictional response.

In the following pages, the experimental conditions are detailed (section 2) along with the main results in terms of stress-strain data, ultrasonic Pwave velocity data, and micro-seismic activity (section 3). The fourth section is dedicated to an analysis and discussion of these results in terms of the MS signatures of shear faulting and fault slip (slow/fast slip), frictional behaviour of the shear fault in relation to the associated MS activity, and a comparison to other rock lithologies.

\section{Description of the experiment}

\subsection{Shale material}

A large core was recovered from the North Sea at a depth of 1643 m below sea bed in a clay-rich shale formation (Campanian, upper Cretaceous). The core was preserved since recovery from depth in several layers of plastic and aluminium wrap with an additional external wax coating. After unpacking, this shale appeared relatively homogeneous, dark grey in colour, with bedding visible inclined at $45^{\circ}$ to the core axis. Twin cylindrical specimens $40 \mathrm{~mm}$ in diameter have been cored along the axis of the original core so that the bedding was also inclined at $45^{\circ}$ to their axis. Their end faces were 
trimmed and ground to be parallel to each other to within $0.02 \mathrm{~mm}$. The final length of the specimens was $81 \mathrm{~mm}$ (long specimen) and $40 \mathrm{~mm}$ (short specimen), respectively. For the coring, trimming and grinding operations, compressed air was used as the cooling fluid. After preparation, the specimens were equilibrated for several days at room conditions $\left(20^{\circ} \mathrm{C}\right.$, relative humidity of 50\%) until stabilisation of their mass at these conditions. After this initial treatment the specimens turned to a light grey colour. The mass evolution of the samples during this initial treatment and their change in color suggest that they lost water (dehydration) by exchange with the atmosphere. The porosity of the shale was estimated to be of the order of $19 \%$ (density: $2370 \mathrm{~kg} / \mathrm{m}^{3}$ ) based on mass measurements conducted on a separate block cut from the original core in its preserved state (immidiately after unpacking the core) and its state after mass stabilisation at a room conditions $\left(20^{\circ} \mathrm{C}\right.$, relative humidity of $\left.50 \%\right)$. Note that this porosity is only a lower bound estimate of the actual porosity of the shale assuming that the core was fully water-saturated in its preserved state and is fully dry in its final equilibrated state $\left(20^{\circ} \mathrm{C}\right.$ and relative humidity of $\left.50 \%\right)$. It is expected that only the so-called "free" water could have evaporated during this treatment, so that the shale specimens are likely in a partially saturated state.

The shorter specimen was used to conduct permeability measurements with nitrogen gas under increasing effective pressure using a steady state method, i.e., constant gas flow imposed at one end of the specimen, and monitoring of the differential pressure build-up and stabilisation across its two ends [25]. The permeability results are summarised in TABLE 1 . The permeability of this shale to nitrogen decreases by almost two orders of mag- 
nitude from $2.1 \times 10^{-5} \mathrm{mD}$ down to $6.9 \times 10^{-7} \mathrm{mD}$ when the effective confining pressure increases from $4 \mathrm{MPa}$ up to $65 \mathrm{MPa}$. This seems to indicate that stress-sensitive pre-existing micro-cracks (damage) are closed by the increasing effective pressure. Such micro-cracks might have been induced by stress release following the recovery of the shale core from depth and/or the dehydration of the specimen at room conditions during initial treatment.

The longer specimen was used to conduct the triaxial deformation experiment with MS monitoring detailed in the remainder of this article.

\subsection{Experimental equipment}

In order to characterise the MS response of the shale to changes in the triaxial stress state, a specific laboratory setup is required to monitor both the deformation of the specimen and the induced MS activity. The experimental setup consists mainly of: (i) a Sanchez Technologies axisymmetric triaxial stress vessel in which a radial and an axial stress can be independently applied to a cylindrical rock specimen; (ii) an Applied Seismology Consultants multichannel ultrasonic/micro-seismic monitoring system (Fig. 1). This apparatus allows the simultaneous acquisition of various types of data on a single rock specimen: (i) radial and (ii) axial deformations, (iii) active ultrasonic monitoring, i.e., ultrasonic $\mathrm{P}$-wave velocities along numerous propagation paths at selected stages of the deformation (called velocity surveys); and (iv) passive monitoring, i.e., induced micro-seismicity (also called acoustic emissions). Note that both active and passive monitoring are conducted using the same array of ultrasonic transducers as described below.

After the initial drying treatment of the long shale specimen at a temperature of $20^{\circ} \mathrm{C}$ and a relative humidity of $50 \%$, four strain gauges are glued 
onto its lateral surface so that four independent directions of deformation are measured (see Figs. 1 and 2): Gauge 1 measures the axial strain along the specimen's axis, at $45^{\circ}$ to the bedding orientation. Gauge 2 measures the circumferential strain orthogonal to the specimen's axis, at $45^{\circ}$ to the bedding; this strain also corresponds to the radial strain, and for sake of simplicity, it will be referred to as radial strain in the remaining of the article. Gauge 3 measures the strain orthogonal to the bedding, at $45^{\circ}$ to the specimen's axis. Gauge 4 measures the strain along the bedding, at $45^{\circ}$ to the specimen's axis. In addition, the average axial displacement between the two ends of the specimen was monitored using three contactless Eddy current displacement transducers located outside the pressure vessel.

\subsection{Experimental protocol}

The shale specimen is inserted into a flexible Viton sleeve and placed inside the pressure chamber of the triaxial stress vessel, which is then closed and filled with oil. The purpose of the flexible sleeve is to isolate the specimen from the hydraulic oil used to apply the radial stress [40]. This specimen is instrumented with: (i) four strain gauges glued directly to its lateral surface, at mid-height; (ii) an array of 16 miniature ultrasonic transducers (6 $\mathrm{mm}$ in diameter) made of piezo-ceramic material with a central resonant frequency of about $0.5 \mathrm{MHz}$. These transducers can be used as ultrasonic sources or receivers attached directly to the lateral surface of the specimen, through sealable holes in the flexible Viton sleeve (Fig. 2).

The experimental deformation protocol consists of: (i) an isotropic stress loading to subject the specimen to a simulated in situ condition with a confining pressure of $10 \mathrm{MPa}$; (ii) a deviatoric stress loading at a constant 
axial displacement rate of $1 \mathrm{~mm} / \mathrm{h}\left(3.5 \times 10^{-6} \mathrm{~s}^{-1}\right)$ up to a point beyond the specimen's failure, which is indicated by a peak in the recorded deviatoric stress; then (iii) a sudden increase of the displacement date to $10 \mathrm{~mm} / \mathrm{h}$ $\left(3.5 \times 10^{-5} \mathrm{~s}^{-1}\right)$ until stabilisation of the recorded deviatoric stress (Fig. 3). The deformation experiment is conducted without injecting water and without controlling the pore pressure at the two ends of the specimen. In view of the testing conditions (partial saturation, no pore fluid injection, and no pore pressure control), the deformation of the specimen is considered as macroscopically drained. Furthermore, the water saturation state and type (uniform or patchy) of the specimen being unknown, the water diffusion length scale within the specimen is also unknown. Therefore, whether the deformation is locally (in the vicinity of the pore water) drained or undrained is unknown.

The aim of the deviatoric stress loading is two-fold: (i) assess the effect of shear faulting and fault slip on the MS response of a shale; and (ii) assess the effect of fault slip rate on the MS activity. The active and passive monitoring equipment is controlled with the Xtream software, while the data management and processing is conducted with the Insite Seismic Processor software.

As part of the active ultrasonic monitoring, at selected stages of the experiment, a P-wave velocity survey is conducted. Each survey consists of 16 consecutive shots, one from each transducer acting as a source. For each source transducer shot, the transmitted waveforms are recorded on the 15 remaining transducers which act as receivers. The waveform recorded at each receiver corresponds to the mechanical vibration transmitted through 
the rock specimen from the source transducer to that particular receiver. In order to improve the signal-to-noise ratio (SNR), each waveform is in fact the result of the stack of several tens of shots from a given source transducer. The waveforms are recorded with a sampling rate of $10 \mathrm{MHz}$ and an amplitude resolution of 12 bits. Each source-receiver pair defines a particular ray path within the specimen, i.e. different directions of wave propagation relative to the specimen's axis and therefore relative to the shale bedding. Each velocity survey typically lasts 30 seconds and consists of 240 waveforms (recorded over 82 microseconds), half of which corresponds to different ray paths within the volume of the specimen. The ultrasonic survey data set acquired during the experiment consists of 10 surveys recorded during the isotropic stress loading after every one or two MPa of confining pressure, and 11 surveys recorded during the deviatoric stress loading.

Between two consecutive velocity surveys, the ultrasonic/micro-seismic system is switched to the passive monitoring mode in order to record any MS activity induced by the stress loading. In this mode, the voltages generated by the ultrasonic transducers sensing a given Micro-seismic events (MSE) are recorded according to a pre-defined trigger logic. Typically, if five transducers exceed a voltage threshold of $15 \mathrm{mV}$ within a time window of 500 nanoseconds, the waveforms from all 16 transducers are recorded for a time window of 82 microseconds. These waveforms are also recorded with a sampling rate of $10 \mathrm{MHz}$ and an amplitude resolution of 12 bits. At the end of the experiment, nearly 500 events have been detected according to this protocol. 


\section{Shear faulting and post-failure slip}

\subsection{Identification of the faulting dynamics}

The shale deformation experiment can be divided into an isotropic stress loading (Phase 0), followed by a deviatoric stress loading. The deviatoric loading stage itself is composed of three phases as discussed below (Figs. 4 and 5).

During Phase 0, the specimen reaches the simulated in situ stress condition with a confining pressure of $10 \mathrm{MPa}$ (point A in Figs. 4 and 5). This phase consists of a step-wise increase of the confining pressure and an equilibration of the specimen at the target condition over several days.

Phase 1 corresponds to the shear faulting (yellow area in Figs. 4 and 5). Axial loading is applied to the specimen at a controlled vertical displacement rate of $1 \mathrm{~mm} / \mathrm{h}$ until the peak axial stress is slightly passed and a first moderate stress drop of about $1 \mathrm{MPa}$ is observed, most probably concomitant with a first slip of the newly formed shear fault (point B in Figs. 4 and 5). The dip angle of the slip surface with respect to a horizontal plane have been estimated post mortem to be about $45^{\circ}$, coinciding approximately with the orientation of the shale bedding. Such an orientation is expected as it coincides with the plane of maximum shear stress in this axisymmetric configuration (see failed sample in Fig. 3).

Phase 2 corresponds to the slow fault slip (blue area in Figs. 4 and 5). The vertical displacement rate is maintained constant so that the newly formed shear fault is slipping at constant rate, while the axial stress drop of about $7 \mathrm{MPa}$ is more pronounced than in Phase 1.

Phase 3 corresponds to the fast fault slip (pink area in Figs. 4 and 5) The 
vertical displacement rate is suddenly increased to $10 \mathrm{~mm} / \mathrm{h}$, which leads to a sudden, moderate and temporary increase of the axial stress of less than 1 MPa (point $\mathrm{C}$ in Figs. 4 and 5). While the axial displacement is maintained constant at that higher rate, after a temporary stabilisation, the axial stress starts to slowly increase to reach a plateau by the end of the experiment (point D in Figs. 4 and 5).

In addition to the evolution with time of the axial stress and displacement, Figs. 4 and 5 also display the evolution of the micro-seismic activity in terms of cumulated number of MSEs and rate of occurrence, respectively. Overall, the cumulated number of events is linearly related to the axial displacement rate, except temporarily after the increase in the imposed displacement rate from 1 to $10 \mathrm{~mm} /$ hour and until the axial stress reaches a plateau. Consistently, the rate of micro-seismic activity is strongly correlated with the imposed displacement rate and the evolution of the axial stress. More details about this part of the dataset are provided in Section 4.3.

\subsection{Analysis of the stress-strain data}

At the end of the isotropic stress loading (Phase 0 aimed at reaching a confining pressure of $10 \mathrm{MPa}$ ), Gages 1, 2, and 3 display a similar amount of strain $\left(0.123 \%\right.$ ), whereas Gage 4 (along the bedding and at $45^{\circ}$ to the specimen's axis) displays about half that amount of strain $(0.072 \%)$. This suggests a significant stress-induced anisotropy of the shale in which the bedding direction is significantly less compliant than the three other measured directions. However, the difference in the magnitude of the recorded strain between Gages 1, 2 and 3 does not clearly reflect a larger compliance in a direction orthogonal to the bedding compared to the two other intermediate 
orientations (at $45^{\circ}$ to the bedding). Over all, the amount of deformation experienced by the specimen during this isotropic stress loading is relatively small, which may explain the lack of sensitivity of the strain gauge recordings and therefore the lack of discrimination between the three directions probed by Gages 1, 2 and 3 .

During the deviatoric stress loading, the four gauges record a significantly larger amount of strain (Fig. 6). The whole dataset recorded during Phases 1,2 and 3 is displayed in this figure. Note however that past the point of strain localisation (shear faulting, slightly beyond the peak stress corresponding to Point B in Fig. 4-6), the local strain measurement provided by the strain gauges is no longer representative of the average strain field over the volume of the specimen because most of the imposed axial displacement is then accommodated by the slipping shear fault. The largest deformation is expectedly recorded along the specimen's axis (about $1 \%$ at the peak stress, along the maximum principal compressive stress), while the radial strain along the minimum principal stress is negative due to Poisson's effect (about $-0.1 \%$ at the peak stress). Gages 3 and 4 record an intermediate amount of strain, consistent with their orientation with respect to the principal stress axes. The difference in magnitude of strain recorded by these two gauges highlights again the existence of a significant anisotropy in the mechanical compliance of the shale. Indeed, in view of their similar orientation with respect to the principal compressive stress axis $\left(45^{\circ}\right)$, they should record a similar deformation if the shale was isotropic. However, it turns out that Gage 3 oriented normal to the bedding records a larger strain than gauge 4 oriented along the bedding due to the mechanical anisotropy of the shale. 
These observations suggest that the quasi-static mechanical compliance of this shale exhibits a significant directional dependency (anisotropy), that is, the compliance across the bedding plane is measurably larger than that along the bedding. This phenomenon has been extensively reported in the literature for many shales of different origin and geological history (e.g., [11, 14, 40, 41, 42] and references therein). It has also been reported for other sedimentary rocks (e.g., [10] and references therein). It is therefore reasonable to assume that while subjected only to a confining pressure, this shale is transversely isotropic (TI) in terms of mechanical properties with a symmetry axis orthogonal to the bedding plane. This symmetry might not hold during deviatoric stress loading because the applied axial stress does not coincide with the shale's original axis of transverse isotropy.

\section{Micro-seismic signature}

\subsection{Analysis of the P-wave velocity data}

The $21 \mathrm{P}$-wave velocity surveys recorded during the experiment were processed with the Insite software. The flight time of the P-wave recorded in each waveform is picked manually rather than by using an automatic algorithm because of the reasonable number of acoustic surveys. This allows systematic quality control of the results with a high degree of confidence. For each source-receiver pair, the $\mathrm{P}$-wave velocity $\mathrm{Vp}$ is calculated using the shortest straight path between the transducers, that is from the closest edge of each transducer to the other (known from the spatial location and dimension of the transducers). 
At a given stage of the experiment, the P-wave velocity along five directions of propagation are estimated, which are referred to as $\operatorname{Vp}\left(90^{\circ}\right), \operatorname{Vp}\left(60^{\circ}\right)$, $\mathrm{Vp}\left(45^{\circ}\right), \mathrm{Vp}\left(30^{\circ}\right)$, and $\mathrm{Vp}\left(0^{\circ}\right)$, where the angles in degrees indicate the propagation direction with respect to the bedding plane. Note that for each nominal ray path orientation $\theta$ with respect to the shale bedding, $\mathrm{Vp}$ is averaged over all source-receiver pairs yielding a ray path orientation comprised in the interval $\left[\theta-5^{\circ}, \theta+5^{\circ}\right]$.

The uncertainty in the estimation of the relative variation of $\mathrm{Vp}$ along a given direction during the experiment is of the order of $1 \%$. This estimate is based on: (i) a waveform sampling period of $0.1 \mu$ s for a propagation time within the specimen comprised between 10 and $15 \mu$ s, and (ii) an uncertainty in the determination of the propagation distance of about $0.1 \mathrm{~mm}$ (caliper) for an average travel distance of about $30 \mathrm{~mm}$. The uncertainty in the estimation of the absolute value of $\mathrm{Vp}$ along a given direction is expected to be higher, of the order of $10 \%$, mainly due to the inherently higher uncertainty of about $1 \mu \mathrm{s}$ with which a human operator can decide for the P-wave arrival time from an experimentally recorded waveform.

During the isotropic loading (Phase 0), and for all propagation directions, a significant increase in $\mathrm{Vp}$ with a confining pressure increase from 0 to $3 \mathrm{MPa}$ is observed, with only slight increase between 3 and $10 \mathrm{MPa}$ (Fig. 7a). Despite the uncertainty in the estimation of the absolute value of $\mathrm{Vp}$ (the worst case scenario is represented by the error bars in Fig. 7a), the relative magnitudes of $\mathrm{Vp}$ along the different propagation directions can be considered as reliable. The elastic anisotropy of the shale is clearly highlighted, with a slow $\operatorname{Vp}\left(90^{\circ}\right)$ and a fast $\operatorname{Vp}\left(0^{\circ}\right)$ velocity across and along the 
bedding, respectively. We also observe that $\operatorname{Vp}\left(60^{\circ}\right), \operatorname{Vp}\left(45^{\circ}\right)$ and $\operatorname{Vp}\left(30^{\circ}\right)$ exhibit intermediate values, inversely proportional to their angular inclination with respect to the bedding plane. This suggests that the shale specimen can reasonably be assumed to be transversely isotropic (TI) in terms of its dynamic elastic response. This phenomenon has also been extensively reported in the literature for many shales of different origin and geological history (e.g., [40, 41] and references therein)

In view of the size of the ultrasonic transducers and the propagation distances within the specimen, the estimated $\mathrm{P}$-wave velocities are assumed to be group (ray) velocities ([12]). However, along the symmetry axis and the symmetry plane of the TI shale, group (ray) and phase velocity coincide. Therefore, Thomsen's parameter $[47] \varepsilon=\left(\operatorname{Vp}\left(0^{\circ}\right)^{2}-\operatorname{Vp}\left(90^{\circ}\right)^{2}\right) / 2 \operatorname{Vp}\left(90^{\circ}\right)^{2}$ quantifying the P-wave anisotropy in a TI medium can be estimated using the measured group velocities (Fig. 7b, d).

The $\mathrm{P}$-wave velocity and the corresponding $\mathrm{P}$-wave anisotropy as measured by Thomsen's $\varepsilon$ parameter exhibit a significant dependency to the confining pressure (Fig. 7a, b): $\varepsilon$ drops from 1.8 to 0.8 between 0 and $3 \mathrm{MPa}$ and remains almost constant from 3 to $10 \mathrm{MPa}$. This suggests a closure of pre-existing micro-cracks (damage) sub-parallel to the bedding with the increase in effective pressure, which is consistent with the dependency of the gas permeability to effective pressure reported in Section 2.1. In contrast, during the deviatoric stress loading (Phases 1 to 3), P-wave velocities appear nearly constant or rise slightly (Fig. 7c), and Thomsen's parameter $\varepsilon$ exhibits a moderate dependency to deviatoric stress (Fig. 7d), decreasing to 0.6 as differential stress increases from 0 to $35 \mathrm{MPa}$. 


\subsection{P-wave velocity model of the shale sample}

In order to spatially locate the MSEs recorded during the experiment, a $\mathrm{P}$-wave velocity model is required. Based on the analysis of the $\mathrm{P}$-wave velocity data, the velocity model should in principle account for the TI nature of the elastic properties of the shale and the variation of the P-wave velocities with stress. However, as the aim is only to locate MSEs recorded during the deviatoric stress loading (Phases 1 to 3 ), and accounting for the fact that the P-wave velocities are not significantly affected by the deviatoric stress during these phases, the velocities recorded at the start of Phase 1 are used to build the required velocity model of the shale, that is when the confining pressure is $10 \mathrm{MPa}$ and the axial stress is zero. Note that this model is only an approximation assuming that the shale specimen is homogeneous.

In addition, because their spatial location is known, the ultrasonic sources shot during the velocity surveys can first be used to assess the validity of both the location (inversion) algorithm and the selected TI velocity model. A Simplex algorithm implemented in the Insite software, and a velocity model based on a slow velocity $\operatorname{Vp}\left(90^{\circ}\right)=2000 \mathrm{~m} / \mathrm{s}$ and an $\varepsilon=0.78$ are used. The orientation of the symmetry axis of this model is inferred from the known orientation of the bedding in the specimen, that is at $45^{\circ}$ to the specimen's axis.

Although this velocity model accounts for the experimentally estimated velocity and anisotropy, at the scale of the specimen used in this experiment, this combination of values produced a distorted pattern of location of the source shots. In an attempt to improve the results and optimise the procedure, several values of the slow velocity $\mathrm{Vp}\left(90^{\circ}\right)$ and the value of $\varepsilon$ are 
tested. The combination that produces the best source shots locations is found to be $\operatorname{Vp}\left(90^{\circ}\right)=1900 \mathrm{~m} / \mathrm{s}$ and $\varepsilon=0.625$. The inversion using these values and applied to 176 ultrasonic shots reflects reasonably well the known position of the ultrasonic array, i.e. the sources clearly locate in the vicinity of the transducers (Fig.8). The remaining mismatch between the recovered and the actual sensor positions can reasonably be attributed to: (i) the progressive loss of transverse isotropy of the shale during the application of the deviatoric stress (not aligned with the original symmetry axis); and (ii) the heterogeneity of the velocity field in the natural shale specimen.

\subsection{Analysis of the induced micro-seismicity}

\subsubsection{Spatio-temporal evolution}

According to the passive monitoring protocol described in Section 2.3, nearly 500 events are detected during the whole experiment, although not all of them are identified as MSEs. Due to the reasonable number of events recorded, a manual check of the acquired data set was possible. A number of events are identified as electronic noise while others are discarded due to the low SNR of the recorded waveforms. Finally, only the events that could be reliably located within the volume of the specimen are selected for further analysis (Fig. 9). This procedure finally leads to the selection of a total of 280 MSEs: 34 during Phase 1 (yellow spheres in Fig. 9), 14 during Phase 2 (blue spheres), and 232 during Phase 3 (pink spheres). The average location error for the whole dataset is $3.5 \mathrm{~mm}$. For an imposed axial displacement of $1 \mathrm{~mm} /$ hour (Phase 2), the average rate of MSEs is $0.07 \mathrm{MSE} /$ second. This value reaches an average of $0.19 \mathrm{MSE} / \mathrm{second}$ over the whole Phase 3 of imposed axial displacement at $10 \mathrm{~mm} /$ hour. Note that only 15 events 
are detected during Phase 0 of confining pressure loading applied to reach the simulated in situ stress. For sake of clarity and because they are not induced by the triaxial loading, these events have been discarded and are not represented in (Fig. 9).

The spatial distribution of the MSEs is clearly not random: they appear distributed along two main planar structures, sub-parallel to the shale bedding (Fig. 10). A first structure, highlighted as a yellow plane, is initiated during Phase 1: few yellow MSEs seem to be distributed over the volume of the specimen, but most of them appear to cluster along the highlighted yellow plane. This reflects an initial diffuse damage, then a first pattern of strain localisation in the vicinity of the yellow plane. The second structure, highlighted as a pink plane, is initiated during Phase 2 (slow slip, blue MSEs) and largely develops during Phase 3 (fast slip, pink MSEs). Note however that the MSEs occurring during Phase 3 do not locate only in the vicinity of the pink plane, but also in the overlap volume between the yellow and pink planes, and on the yellow plane to a lesser extent. In addition, there are few yellow MSEs located on the pink plane, which suggests that shear faulting could have been initiated simultaneously on both planes, then the upper shear plane takes over the lower one and accommodates most of the rock shortening but the end of the experiment.

The above results are derived from the combined use of active ultrasonic and passive MS monitoring of the deformation process. Both monitoring techniques are based only on the picking of the time of arrival of the first phase in the recorded waveforms. 


\subsubsection{Moment tensor analysis}

The first motion polarities and relative amplitudes of the waveforms recorded for a given MSE can be used to estimate its source mechanism, similar to the approach widely used in seismology to define the source mechanism of earthquakes. This method, generally known as the Moment Tensor Inversion (MTI), is implemented in the Insite software and is used here to characterise the focal mechanism of the recorded MSEs $[37,52,53,54]$. However, in order to obtain reliable MTI results, the analysis must be restricted to MSEs of sufficiently high quality, which represent a relatively small subset of all the spatially located MSEs. The MTI has been carried out on all the MSEs located spatially. The results reported Figure 11 fulfil the additional criteria: (i) a spatial location error strictly lower than $5 \mathrm{~mm}$; (ii) a mean error factor lower than 17; (iii) an inversion quality index lower than 4.4; and (iii) a T-k error norm lower than 0.3. The mean error factor measures the difference between the amplitude residual and the estimated uncertainty in the original amplitude measurement. The inversion quality factor is based on the 6x6 covariance matrix and depends on the Green's functions used, rather than the amplitudes. It is computed from the sum of the squares of the elements of the covariance matrix. The T-k error norm is the RMSE of the errors on the deviatoric $(\mathrm{T})$ and isotropic $(\mathrm{k})$ parameters representing the source [23]. The threshold values of the mean error factor, inversion quality index and T-k error norm have been selected as the mean values obtained for the whole set of spatially located MSEs to which the MTI has been carried out. With such criteria, 42 MSEs have been selected: 11 MSEs in Phase 1, 6 MSEs in Phase 2 and 25 in Phase 3. The average amplitude residual 
parameter for these 42 MSEs is 0.21 , and the standard deviation is 0.08 .

Figure 11 shows the spatial distribution of the 42 MSEs within the shale specimen. For each MSE, the detecting ultrasonic sensors covered a reasonable portion of the solid angle around it, which allowed for a reliable MTI. In this figure, MSEs \#79 in Phase 1, \#128 in Phase 2 and \#259 in Phase 3 have been highlighted because they exhibit the largest location magnitude for each phase. For each of these three MSEs, the focal mechanism is represented by a focal sphere plot, i.e., the so-called beachballs widely used in seismology. The sensors that detected the MSE are represented by small discs in the beachballs, with the convention that black and white discs represent compressional and dilatational first motion, respectively. The fault plane is calculated using the first-motion polarity of the P-wave picked in the waveform recorded by each sensor that detected this MSE and is represented by red circles in each focal sphere plot. The orientation of the fault plane is consistent with that of the fault planes identified statistically by the spatial distribtion of the MSEs and by the post-mortem observation of the sample.

The MTI procedure yields the focal mechanism of each MSE as a combination of three basic modes, with usually a dominant mode: ISO, stands for isotropic dilatation, DC for double-couple (shear), and CLVD for compensated linear vector dipole [44, 52]. Hudson's so-called T-k plot ([23]) is wellsuited to display such decomposition in an equal-area graph (Fig. 11) where the T-axis stands for the deviatoric component of the mechanism (shear deformation) and $\mathrm{k}$ stands for the normal/isotropic component (volumetric deformation, either positive-explosive or negative-implosive).

Figure 13 reports graphically the results of the moment tensor decom- 
position of the selected high quality MSEs. The top graph shows the detailed decomposition into DC, CLVD and ISO MSEs; the lower graph shows the simpler decomposition into shear (DC) and non-shear (ISO+CLVD) MSEs. These plots suggest a transition form non-shear dominated to sheardominated micro-seismic activity when the rock evolves from initial failure to larger and faster slip along the fault

\section{Discussion}

\subsection{Shear faulting in the laboratory and relay ramp structures in the field}

The post-mortem picture of the failed specimen and the location of the recorded MSEs are in good agreement (see Fig. 10). Although the picture of the specimen cannot show the internal structure of the shear faults, their emergence at the external boundary of the specimen is in agreement with the location of the MSEs at this boundary. Two different planar structures are identified from the spatio-temporal location of the 280 MSEs (Figs. 9 and $10)$.

These results suggest that the lower shear fault (yellow plane) is most active (accommodates most of the imposed axial dis- placement) at the early stages after strain localisation (Phase 1), although few yellow events are already located on the top part of the upper shear fault. However, during this phase no clustering of MSE is observed on this upper plane. During Phase 2, a transition of the micro-seismic activity is observed from the lower shear fault toward the upper shear fault (pink plane). During Phase 3 most of the imposed axial displacement is accommodated by the upper shear fault, although few events are still located on the lower shear fault, indicating that 
it is not entirely inactive. This is consistent with the sequence of events associated with a typical relay ramp structure formed during the growth of normal fault systems in large scale geology

This upward transition from the lower to the upper SF is particularly visible in Figure 10 where the MSEs in each phase have been colour-coded according to their time of occurrence within the phase. More precisely, once the yellow SF is formed and its activity slows down at the end of Phase 1, the blue MSEs of Phase 2 first appear at the lower end of the pink SF then the MS activity migrates upward along this SF and approaches the boundary of the specimen. Once the pink SF is largely developed, part of the MS activity (pink MSEs) locates in the overlap volume between the two SF planes. In summary, it seems that the lower shear fault forms first (yellow plane), before the micro-seismic activity (blue spheres) migrates upward and the the upper shear fault forms and accommodates most of the subsequently imposed axial displacement (pink plane). This is essentially similar to typical sequence of events associated with either (i) the formation of a relay ramp structure during the growth of normal fault systems in large scale geology; or (ii) fractures growing towards one another and overlapping.

\subsection{Silent failure, slow slip and slip rate dependency}

Phase 1 is quasi-aseismic (only $34 \mathrm{MSEs}$ ), at least in the $0.5 \mathrm{MHz}$ range of sensitivity of the ultrasonic transducers used in the experiment (about 0.1 to $1 \mathrm{MHz}$ ). This is surprising because Phase 1 corresponds to the failure of the clay-rich rock and contrasts with other sedimentary or crystalline rocks (e.g., sandstones, granites) for which large amounts of precursory MSEs are usually recorded prior to the macroscopic failure, and failure itself has been 
reported to generate a much stronger MS activity (thousands of events). Phase 2 of slow slip on the yellow shear fault induces very small amount of MS activity: clays might be acting as a ?lubricant? on the fault(s) at that slip rate. Silent or almost silent failures have already been reported in materials being deformed close to the brittle ductile transition, for instance Carrara marble [43], or Volterra gypsum at room temperature [5]. In all cases, ?silent? failures are accompanied by slow slip and stress drop, i.e. the macroscopic fault releases the stress too slowly for the rupture and the slip to accelerate and start radiating elastic waves. As such, slow failures can be viewed as quasi-static failures in the Griffith sense, i.e., the entire energy release rate is dissipated at the rupture tip into fracture surface, damage and plastic strain. Note that slow failures are not always silent, because at the microscopic scale, damage at the crack tip can actually also radiate elastic waves and be associated to MSEs, as for instance during quasi static fault growth in granite [33], slow failure in porous basalt [4] or shear or compaction band formation in sandstones $[15,17]$. Hence, both the growth of macroscopic fracture and the accumulation of microscopic damage are ?silent? in the frequency range investigated in these experiments. This suggests that shale and clays are indeed potential good candidate to host slow slip within shallow accretionary prism [19, 22], or in the shallow section of continental faults [50].

In contrast, Phase 3 of slip acceleration from $1 \mathrm{~mm} / \mathrm{h}$ to $10 \mathrm{~mm} / \mathrm{h}$, i.e. slip slip velocities slightly larger than that observed during slow earthquakes which are typically of the order of several tens of cm per year only [20], generates a significant amount of MS activity. During that fast slip phase, the $\mathrm{AE}$ rate and the slip are proportional so there seems to be a significant rate 
dependency of the lubrication potential of clays. In Figure 13, the slip acceleration triggers an instantaneous increase in the friction coefficient, which is typical of the direct effect [35]. After that, the fault first weakens with increasing slip, then starts to re-strengthen after a few millimetres of slip, exhibiting thus the typical velocity strengthening behaviour observed for clay minerals [38]. It is interesting to note that during that phase, nevertheless, numerous MSEs are observed, probably linked to the dynamic shear failure of small asperities on the fault plane, as demonstrated by the inverted focal mechanisms (see Fig 11). These observations highlight the possible interactions between small asperities and slow slip of a velocity-strengthening fault [3], which could be considered as a realistic experimental analogue of natural observations of non-volcanic tremors and (very) low-frequency earthquakes triggered by slow slip events $[19,21]$.

\section{Conclusion}

We have demonstrated that it is possible to apply laboratory techniques usually employed for monitoring micro-seismicity on reservoir or crystalline rocks to anisotropic shale specimens. The data acquired during this triaxial experiment allowed us (i) to quantify the P-wave (dynamic) anisotropy of the shale and its evolution with stress; (ii) monitor the micro-seismic activity occurring during failure and subsequent fault slip at two different rates. The gas permeability as well as the P-wave velocity data and their respective sensitivity to pressure suggest the existence of micro-cracks in this partially dry shale specimen at room conditions. although these micro-cracks tend to close with increasing effective confining pressure. The spatio-temporal loca- 
tion of the MSEs recorded during the three phases of the experiment (failure, slow fault slip, fast fault slip) indicates that two shear fault planes where in competition after the initial strain localisation that occurred near the peak axial stress. The evolution of these two shear fault planes as derived from the micro-seismic monitoring is consistent with the sequence of events associated with a typical relay ramp structure formed during the growth of normal fault systems in large scale geology. The moment tensor inversion carried out on the highest quality MSEs suggests a transition form non-shear dominated to shear-dominated micro-seismic activity when the rock evolves from initial failure to larger and faster slip along the fault. The spatial orientation of the fault plane obtained on the highest magnitude MSE for each phase is consistent with the macroscopic orientation of the shear faults. The frictional behaviour of the shear faults highlights the possible interactions between small asperities and slow slip of a velocity-strengthening fault, which could be considered as a realistic experimental analogue of natural observations of non-volcanic tremors and (very) low-frequency earthquakes triggered by slow slip events.

\section{Acknowledgments}

This research work was sponsored by BP under the contract number BPO-06-01329. This support is gratefully acknowledged. 


\section{References}

[1] Amitrano D., Brittle-ductile transition and associated seismicity: Experimental and numerical studies and relationship with the b value, Journal of Geophysical Research-Solid Earth, 108(B1), doi:10.1029/2001JB000680, 2003.

[2] Amann F., Button E.A., Evans K.F., Gischig V.S., and Blümel M., Experimental study of the brittle behavior of clay shale in rapid unconfined compression, Rock Mechanics and Rock Engineering, 44, 415 - 430, 2011.

[3] Ariyoshi K., Hori T., Ampuero J.P., Kaneda Y., Matsuzawa T., Hino R. and Hasegawa A., Influence of interaction between small asperities on various types of slow earthquakes in a 3 -D simulation for a subduction plate boundary, Gondwana Research, 16, 534 - 544, 2009.

[4] Benson P.M., Thompson B.D., Meredith P.G., Vinciguerra S. and Young R.P., Imaging slow failure in triaxially deformed Etna basalt using 3D acoustic?emission location and X?ray computed tomography, Geophysical Research Letters, 34(3), 2007.

[5] Brantut N., Schubnel A. and Guéguen Y., Damage and rupture dynamics at the brittle?ductile transition: The case of gypsum, Journal of Geophysical Research-Solid Earth, 116(B1), 1978 - 2012, 2011.

[6] Chang S.-H., and Lee C.-I., Estimation of cracking and damage mechanisms in rock under triaxial compression by moment tensor analysis of acoustic emission, International Journal of Rock mechanics and Mining Sciences, 41, 1069 - 1086, 2004. 
[7] Charalampidou E.-M., Hall S.A., Stanchits S., Lewis H., and Viggiani G., Characterization of shear and compaction bands in a porous sandstone deformed under triaxial compression, Tectonophysics, 503, 8 - 17, 2011.

[8] Charalampidou E.-M., Stanchits S., Kwiatek G., and Dresen G., Brittle failure and fracture reactivation in sandstone by fluid injection, European Journal of Environmental and Civil Engineering, 19, 564 - 579, 2015.

[9] Dautriat J., Sarout J., David C., Bertauld D., and Macault R., Remote monitoring of the mechanical instability induced by fluid substitution and water weakening in the laboratory, Physics of the Earth and Planetary Interiors, This issue.

[10] David C., Dautriat D., Sarout J., Delle Piane C., Menéndez B., Macault R., and Bertauld D., Mechanical instability induced by water weakening in laboratory fluid injection tests, Journal of Geophysical Research-Solid Earth, 120, 4171 - 4188, doi:10.1002/ 2015JB011894.

[11] Delle Piane C., Dewhurst D.N., Siggins A.F. and Raven M., Stressinduced anisotropy in brine saturated shale, Geophysical Journal International, 184, 897 - 906, 2011.

[12] Dellinger J., and Vernik L., Do travel times in pulse transmission experiments yield anisotropic group or phase velocities?, Geophysics, 41, $1774-1779,1994$.

[13] Dewhurst D.N. and Siggins A.F., Impact of fabric, microcracks and 
stress field on shale anisotropy, Geophysical Journal International, 165, 135 - 148, 2006.

[14] Dewhurst D.N., Siggins A.F., Sarout J. and Raven M., Geomechanical and ultrasonic characterization of a Norwegian Sea shale, Geophysics, 76, WA101 - WA111, 2011.

[15] Fortin J., Stanchits S., Dresen G., and Gueguen Y., Acoustic emission and velocities associated with the formation of compaction bands in sandstone, Journal of Geophysical Research-Solid Earth, 111, B10203, doi:10.1029/2005JB003854, 2006.

[16] Fortin J., Stanchits S., Dresen G., and Gueguen Y., Damage evolution, acoustic emissions and elastic wave velocities in porous carbonate rocks, AGU Fall Meeting Abstracts, \#T23D-0539, 2009.

[17] Fortin J., Stanchits S., Dresen G., and Gueguen Y., Acoustic emissions monitoring during inelastic deformation of porous sandstone: Comparison of three modes of deformation, Pure and Applied Geophysics, 166, $823-841,2009$.

[18] Guglielmi Y., Cappa F., Avouac J.-P., Henry P., and Elsworth D., Seismicity triggered by fluid injection-induced aseismic slip, Science, 348, $1224-1226,2015$.

[19] Hirose H., Asano Y., Obara K., Kimura T., Matsuzawa T., Tanaka S. and Maeda T., Slow earthquakes linked along dip in the Nankai subduction zone, Science, 330, 1502 - 1502, 2010. 
[20] Ikari M.J., Ito Y., Ujiie K. and Knopf A.J., Spectrum of slip behaviour in Tohoku fault zone samples at plate tectonic slip rates, Nature Geosciences, 2015.

[21] Ito Y., Obara K., Shiomi K., Sekine S. and Hirose H., Slow earthquakes coincident with episodic tremors and slow slip events, Science, 315, 503 $-506,207$.

[22] Ito Y., Hino R., Kido M., Fujimoto H., Osada Y., Inazu D. and Mishina M., Episodic slow slip events in the Japan subduction zone before the 2011 Tohoku-Oki earthquake, Tectonophysics, 600, 14 - 26, 2013.

[23] Hudson J.A., Pearce R.G. and Rogers R.M., Source type plot for inversion of the moment tensor, Journal of Geophysical Research-Solid Earth, 91, $765-774,1989$.

[24] Johnston J.E. and Christensen N.I., Seismic anisotropy of shales, Journal of Geophysical Research-Solid Earth, 100(B4, 5991 - 6003, 1995.

[25] Josh M., Esteban L., Delle Piane C., Sarout J., Dewhurst D.N. and Clennell M.B., Laboratory characterisation of shale properties, Journal of Petroleum Science and Engineering, 88-89, 107 - 124, 2012.

[26] Kusunose K., Lei X., Nishizawa O. and Satoh T., Effect of grain size on fractal structure of acoustic emission hypocenter distribution in granitic rock, Physics of the Earth and Planetary Interiors, 67, 194 - 199, 1991.

[27] Le Gonidec Y., Sarout J., Wassermann J. and Nussbaum C., Damage initiation and propagation assessed from stress-induced microseismic 
events during a mine-by test in the Opalinus Clay, Geophysical Journal International, 198, 126 - 139, 2014.

[28] Lei X., Kusunose K., Satoh T. and Nishizawa O., The hierarchical rupture process of a fault: an experimental study, Physics of the Earth and Planetary Interiors, 137, 213 - 228, 2003.

[29] Lei X., Masuda K., Nishizawa O., Jouniaux L., Liu L., Ma W., Satoh T. and Kusunose K., Detailed analysis of acoustic emission activity during catastrophic fracture of faults in rock, Journal of Structural Geology, 26, 247 - 258, 2004.

[30] Lei X., Nishizawa O., Kusunose K., Cho A., Satoh T. and Nishizawa O., Compressive failure of mudstone samples containing quartz veins using rapid AE monitoring: the role of asperities, Tectonophysics, 328, 329 $340,2000$.

[31] Lei X. and Satoh T., Indicators of critical point behavior prior to rock failure inferred from pre-failure damage, Tectonophysics, 431, 97 - 111, 2007.

[32] Lockner D.A., The role of acoustic emission in the study of rock fracture, International Journal of Rock Mechanics and Mining Sciences, 30, 883 - 899, 1993.

[33] Lockner D.A., Byerlee J.D., Kuksenko V., Ponomarev A. and Sidorin A., Quasi-static fault growth and shear fracture energy in granite, Nature, 350, 39 - 42, 1991. 
[34] Lowry A.R., Larson K.M., Kostoglodov V. and Bilham R., Transient fault slip in Guerrero, southern Mexico, Geophysical Research Letters, 28, 3753 - 3756, 2001.

[35] Marone C., Laboratory-derived friction laws and their application to seismic faulting, Annual Review of Earth and Planetary Sciences, 26, $643-696,1998$.

[36] Niemeijer A.R. and Spiers C.J., Influence of phyllosilicates on fault strength in the brittle-ductile transition: insights from rock analogue experiments, Special publication-Geological Society of London, 245, 303, 2005.

[37] Pettitt W.S., Baker C., Young R.P., Dahlstrm L.-O. and Ramqvist G., The assessment of damage around critical engineering structures using induced seismicity and ultrasonic techniques, Pure and Applied Geophysics, 159, 179 - 195, 2002.

[38] Safer D.M. and Marone C., Comparison of smectite-and illite-rich gouge frictional properties: application to the updip limit of the seismogenic zone along subduction megathrusts, Earth and Planetary Science Letters, 215, 219 - 235, 2003.

[39] Sarout J., Delle Piane C., Nadri D., Esteban L. and Dewhurst D.N., A robust experimental determination of Thomsen's $\delta$ parameter, Geophysics, 80, A19 - A24, 2015.

[40] Sarout J., Esteban L., Delle Piane C., Maney B. and Dewhurst D.N., 
Elastic anisotropy of Opalinus Clay under variable saturation and triaxial stress, Geophysical Journal International, 198, 1662 - 1682, 2014.

[41] Sarout J. and Guéguen Y., Anisotropy of elastic wave velocities in deformed shales: Part 1-Experimental results, Geophysics, 73, D75 - D89, 2008.

[42] Sarout J., Molez L., Guéguen Y. and Hoteit N., Shale dynamic properties and anisotropy under triaxial loading: Experimental and theoretical investigations, Physics and Chemistry of the Earth, 32, 896 - 906, 2007.

[43] Schubnel A., Walker E., Thompson B.D., Fortin J., Guéguen Y. and Young R.P., Transient creep, aseismic damage and slow failure in Carrara marble deformed across the brittle?ductile transition, Geophysical Research Letters, 33(17), 2006.

[44] Š́́lený J. and Milev A., Source mechanism of mining induced seismic events: Resolution of double couple and non double couple models, Tectonophysics, 456, 3 - 15, 2008.

[45] Stanchits S., Mayr S., Shapiro S. and Dresen G., Fracturing of porous rock induced by fluid injection, Tectonophysics, 503, 129 - 145, 2011.

[46] Talebi S., Boone T.J. and Eastwood J.E., Injection-induced microseismicity in Colorado shales, Pure and Applied Geophysics, 153, 95 - 111, 1998.

[47] Thomsen L., Weak elastic anisotropy, Geophysics, 51, 1954 - 1966, 1986. 
[48] Vernik L. and Liu X., Velocity anisotropy in shales: A petrophysical study, Geophysics, 62, 521 - 532, 1997.

[49] Warpinski N.R., Du J. and Zimmer U., Measurements of hydraulicfracture-induced seismicity in gas shales, Society of Petroleum Engineers, 27, SPE-151597-PA, doi:10.2118/151597-PA, 2012.

[50] Wei M. and Kaneko Y., Liu Y. and McGuire J.J., Episodic fault creep events in California controlled by shallow frictional heterogeneity, Nature Geoscience, 6, 566-570, 2013.

[51] Wong T.F. and Baud P., The brittle-ductile transition in porous rock: A review, Journal of Structural Geology, 44, 25-53, 2012.

[52] Young R.P., Hazzard J.F. and Pettitt W.S., Seismic and micromechanical studies of rock fracture, Geophysical Research Letters, 27, 1767 $1770,2000$.

[53] Young R.P. and Collins D.S., Seismic studies of rock fracture at the underground research laboratory, Canada, International Journal of Rock Mechanics and Mining Sciences, 38, 787 - 799, 2001.

[54] Young R.P., Collins D.S., Reyes-Montes J.M. and Baker C., Quantification and interpretation of acoustic emission and microseismicity at the underground research laboratory, Canada, International Journal of Rock Mechanics and Mining Sciences, 41, 1317 - 1327, 2004. 


\section{Tables}

Table 1: Nitrogen gas permeability of the partially saturated shale measured at three effective pressure states using a steady state method

Confining pressure Pore pressure Effective pressure Permeability Permeability

\begin{tabular}{ccccc}
$(\mathrm{MPa})$ & $(\mathrm{MPa})$ & $(\mathrm{MPa})$ & $\times 10^{-19} \mathrm{~m}^{2}$ & $\times 10^{-7} \mathrm{mD}$ \\
\hline \hline 10 & 6 & 4 & 211 & 213 \\
50 & 15 & 35 & 28.3 & 28.7 \\
80 & 15 & 65 & 6.8 & 6.9 \\
\hline
\end{tabular}




\section{List of Figures}

1 Experimental setup including (clockwise from top left): the triaxial stress vessel; the rock specimen enclosed in a flexible Viton sleeve, instrumented with 16 ultrasonic P-wave transducers and connected to 16 pulser-amplifiers and 4 strain gages; the strain monitoring computer; and the ultrasonic/microseismic monitoring computer. . . . . . . . . . . . . . 43

2 Spatial location of the ultrasonic sensors represented around the cylindrical shale specimen (right panel), and in an antipodal equal-angle projection (left panel). Two ultrasonic transducers became inoperative at the early stages of the experiment (represented in red). The four strain gages attached to the shale sample are also represented. . . . . . . . . . . . . 44

3 Triaxial loading path: (i) confining pressure loading to reach the simulated in situ stress state of $10 \mathrm{MPa}$ (green line); (ii) axial loading up to the peak stress $(36.77 \mathrm{MPa})$ and stress drop (30.36 MPa) at a constant axial displacement rate of $1 \mathrm{~mm} /$ hour (plain red line); (iii) axial loading at a constant displacement rate of $10 \mathrm{~mm} /$ hour during which the axial stress variation in non monotonic (sudden increase to $31.09 \mathrm{MPa}$, slower decrease to $29.92 \mathrm{MPa}$, then even slower increase to reach a plateau at 32.82 $\mathrm{MPa}$. The failed specimen obtained after the experiment is pictured on the right hand side. . . . . 45 
4 Evolution with time of the total axial and radial stresses, axial displacement and cumulative number of micro-seismic events during Phases 1 (A to $\mathrm{B}$ in yellow), 2 ( $\mathrm{B}$ to $\mathrm{C}$ in blue) and 3 (C to D in pink) of the experiment. Over all, the cumulative number of events is linearly related to the axial displacement rate, except temporarily after the increase in the imposed displacement rate from 1 to $10 \mathrm{~mm} /$ hour and until the axial stress reaches a plateau. . . . . . . . . . . . . . . 46

$5 \quad$ Evolution with time of the total axial and radial stresses, axial displacement and rate of micro-seismic activity during Phase 1 (A to $\mathrm{B}$ in yellow), 2 ( $\mathrm{B}$ to $\mathrm{C}$ in blue) and 3 ( $\mathrm{C}$ to $\mathrm{D}$ in pink) of the experiment. The rate of micro-seismic activity (amplitude of the green curve) is strongly correlated with the imposed displacement rate (slope of the blue cuve in the lower graph) and the evolution of the axial stress (amplitude of the blue curve in the upper graph). . . . . . . . . . . . . 47

6 Stress-strain data during Phase 1 (A to B), 2 (B to C) and 3 (C to D) of the experiment. The orientation of the strain gauges with respect to the shale bedding and the specimen's axis are also shown. The strain recorded by the gauges illustrates the mechanical anisotropy of the shale. . . . . . . . . . . . . . . . 48 
7 Evolution of P-wave group (ray) velocity and anisotropy (Thomsen's $\varepsilon$ parameter) with confining pressure and deviatoric loading. P-wave velocity data are indicated with a $10 \%$ error bar $(+/-5 \%)$. The magnitude of the $\mathrm{P}$-wave velocity as a function of the propagation direction with respect to the bedding illustrates the elastic anisotropy of the shale. This anisotropy decreases significantly with increasing confining pressure, and is virtually not sensitive to the axial stress, at least until the strain localises in a shear fault and the specimen fails. The non-linear variation of the $\mathrm{P}$-wave velocity with confining pressure up to about $4 \mathrm{MPa}$ suggests the existence of damage in the shale specimen at room pressure; the linear variation of the $\mathrm{P}$-wave velocity with confining pressure above $4 \mathrm{MPa}$ suggests the existence of intrinsic anisotropy, most likely associated the preferred alignement of clay platelets/particles. . . . . . . . . 49

8 Spatial and temporal location of the ultrasonic sources shot during the velocity surveys. The squares represent the nominal position of the centre of the ultrasonic sensors; the spheres represent the location of the sources obtained by inversion using the selected velocity model. . . . . . . . . . . . . . 50 
9 Spatial and temporal location of the micro-seismic events recorded during the three phases of the deviatoric loading: in yellow for Phase 1; in blue for Phase 2; and in pink for Phase 3. The micro-seismic activity suggests the existence of two overlapping shear fault planes. Part of the micro-seismic activity locates in the overlap volume between these two planes. A feature similar to relay ramps observed in large scale structural geology. . . . . . . . . . . . . . . . . 51

10 Spatial and temporal location of the recorded MSEs separated into the three phases of the experiment. For each phase, the color of each event is scaled to its time of occurence, i.e., first events of the phase in green and last events in red. These results suggest that the lower shear fault (yellow plane) is most active (accommodates most of the imposed axial displacement) at the early stages after strain localisation (Phase 1). During Phase 2, a transition of the micro-seismic activity is observed from the lower shear fault toward the upper shear fault (pink plane). During Phase 3 most of the imposed axial displacement is accommodated by the upper shear fault although few events are still located on the lower shear fault, indicating that it is not entirely inactive. This is consistent with the sequence of events associated with a typical relay ramp structure formed during the growth of normal fault systems in large scale geology. . . . . . . . . . . . . . . . 52 
11 Spatial location, T-k decomposition in Hudson's diagram [23], and moment tensor solution of the MSE with largest magnitude in each of the three phases of the experiment: MSE \#79 in Phase 1, MSE \#128 in Phase 2 and MSE \#259 in Phase 3.53

12 Results of the moment tensor decomposition of the selected high quality MSEs. The top plot shows the detailed decomposition into DC, CLVD and ISO MSEs; the lower plot shows the simpler decomposition into shear and non-shear MSEs (see main text for details). . . . . . . . . . . . . . . . . 54

13 Fault frictional behaviour and MS activity during Phases 2 and 3. The fault slip is calculated from the measured postfailure axial displacement and the orientation of the fault plane determined post mortem to be approximately at $45^{\circ}$ to the specimen's axis. . . . . . . . . . . . . . . 55 
${ }_{891}$ Figures 

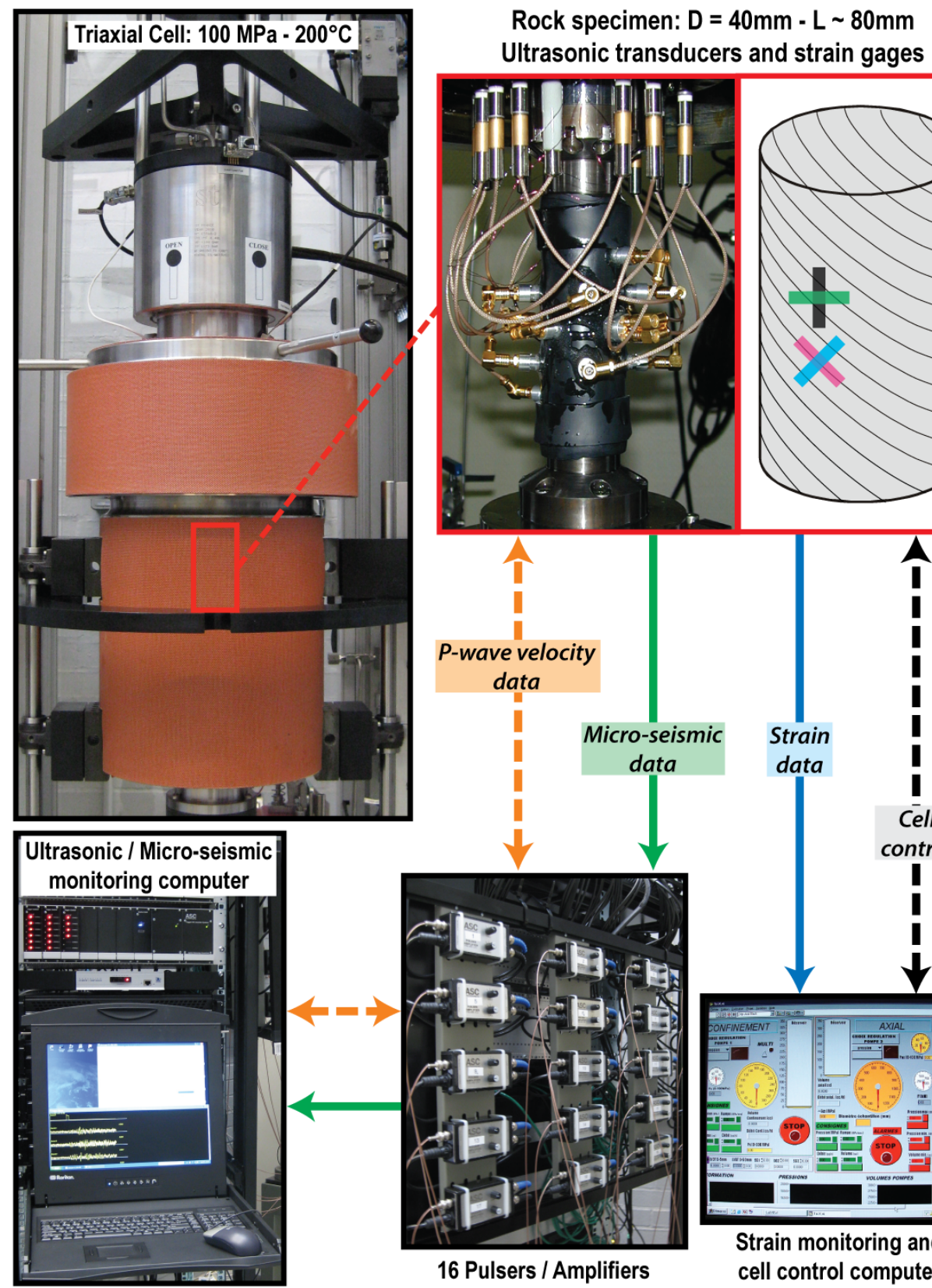

16 Pulsers / Amplifiers cell control computer

Figure 1: Experimental setup including (clockwise from top left): the triaxial stress vessel; the rock specimen enclosed in a flexible Viton sleeve, instrumented with 16 ultrasonic Pwave transducers and connected to 16 pulser-amplifiers and 4 strain gages; the strain monitoring computer; and the ultrasonic/micro-seismic monitoring computer. 


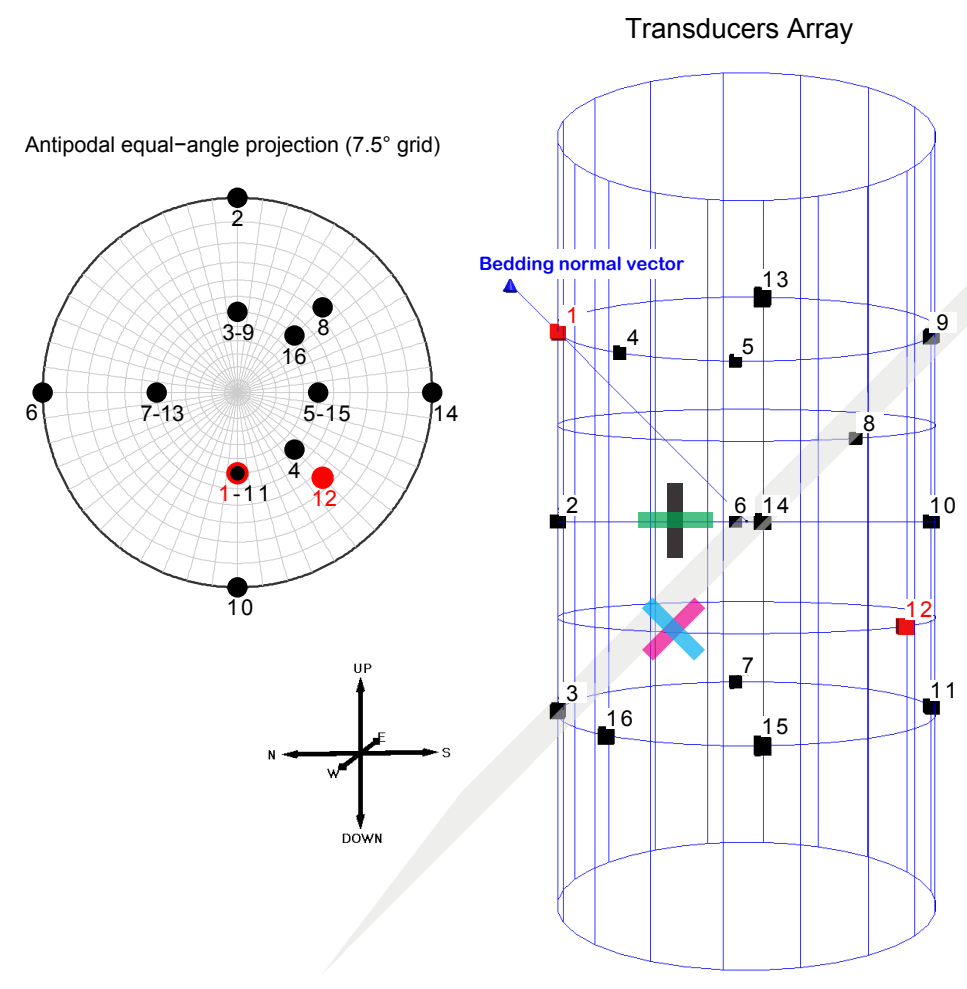

Figure 2: Spatial location of the ultrasonic sensors represented around the cylindrical shale specimen (right panel), and in an antipodal equal-angle projection (left panel). Two ultrasonic transducers became inoperative at the early stages of the experiment (represented in red). The four strain gages attached to the shale sample are also represented. 


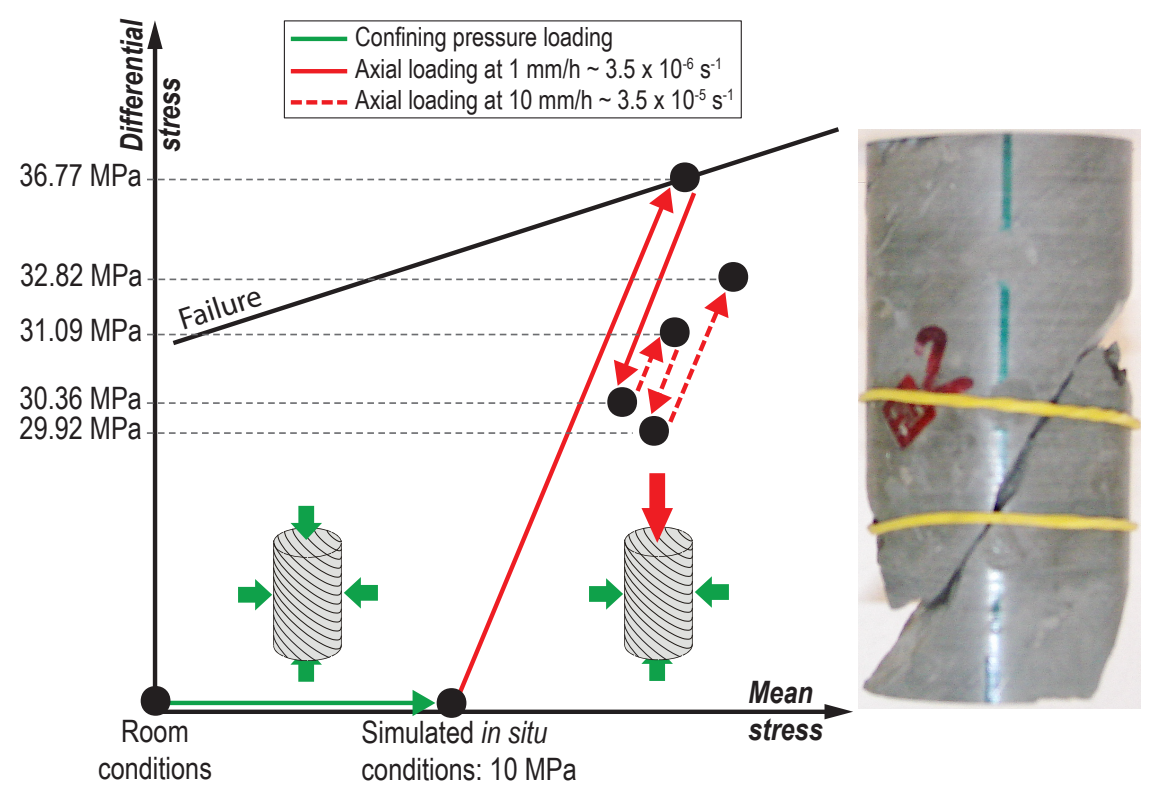

Figure 3: Triaxial loading path: (i) confining pressure loading to reach the simulated in situ stress state of $10 \mathrm{MPa}$ (green line); (ii) axial loading up to the peak stress (36.77 $\mathrm{MPa})$ and stress drop (30.36 MPa) at a constant axial displacement rate of $1 \mathrm{~mm} /$ hour (plain red line); (iii) axial loading at a constant displacement rate of $10 \mathrm{~mm} /$ hour during which the axial stress variation in non monotonic (sudden increase to $31.09 \mathrm{MPa}$, slower decrease to $29.92 \mathrm{MPa}$, then even slower increase to reach a plateau at $32.82 \mathrm{MPa}$. The failed specimen obtained after the experiment is pictured on the right hand side. 

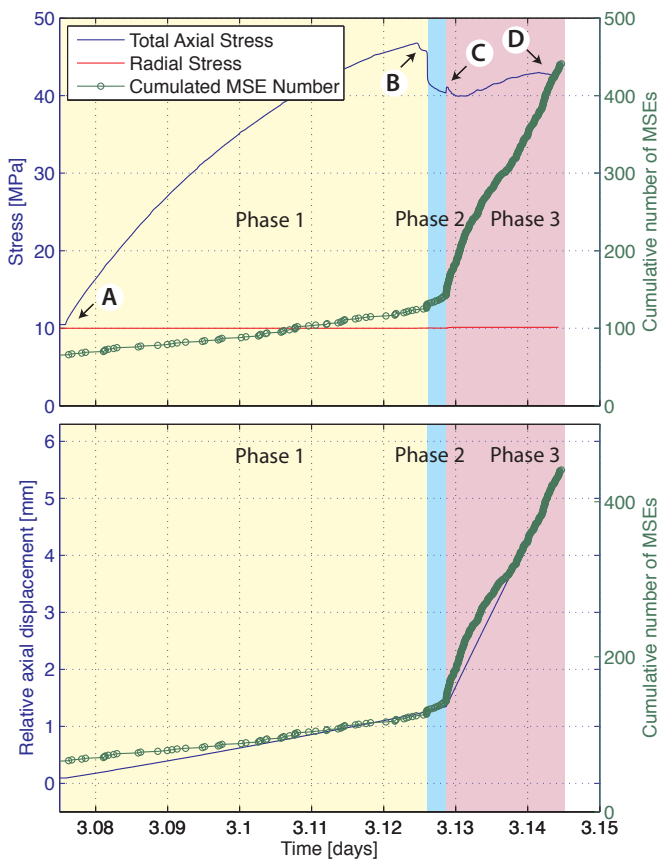

Figure 4: Evolution with time of the total axial and radial stresses, axial displacement and cumulative number of micro-seismic events during Phases 1 (A to B in yellow), 2 (B to $\mathrm{C}$ in blue) and 3 (C to $\mathrm{D}$ in pink) of the experiment. Over all, the cumulative number of events is linearly related to the axial displacement rate, except temporarily after the increase in the imposed displacement rate from 1 to $10 \mathrm{~mm} /$ hour and until the axial stress reaches a plateau. 


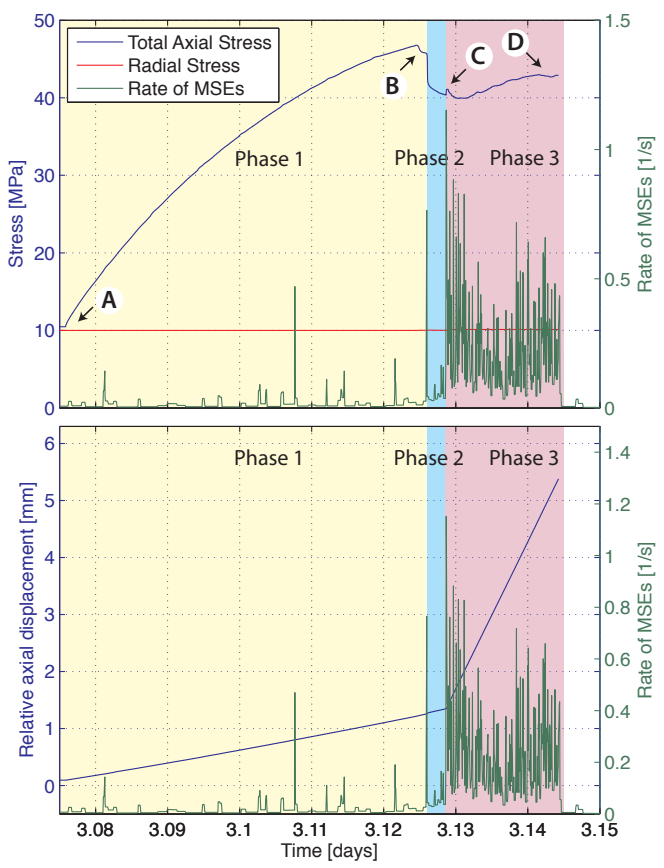

Figure 5: Evolution with time of the total axial and radial stresses, axial displacement and rate of micro-seismic activity during Phase 1 (A to B in yellow), 2 (B to C in blue) and 3 (C to $\mathrm{D}$ in pink) of the experiment. The rate of micro-seismic activity (amplitude of the green curve) is strongly correlated with the imposed displacement rate (slope of the blue cuve in the lower graph) and the evolution of the axial stress (amplitude of the blue curve in the upper graph). 


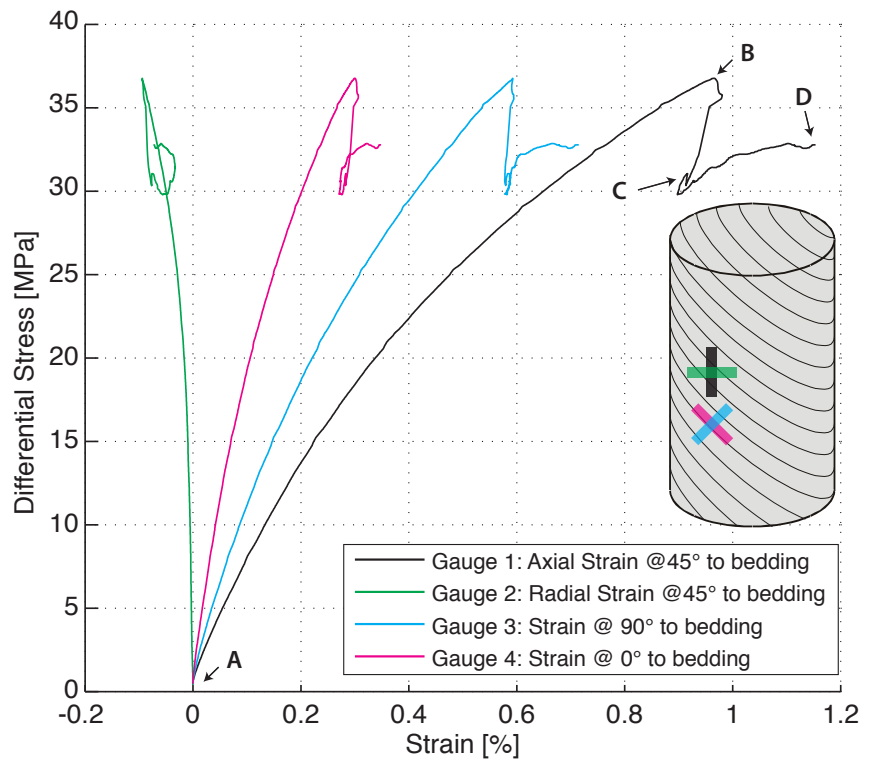

Figure 6: Stress-strain data during Phase 1 (A to B), 2 (B to C) and 3 (C to D) of the experiment. The orientation of the strain gauges with respect to the shale bedding and the specimen's axis are also shown. The strain recorded by the gauges illustrates the mechanical anisotropy of the shale. 

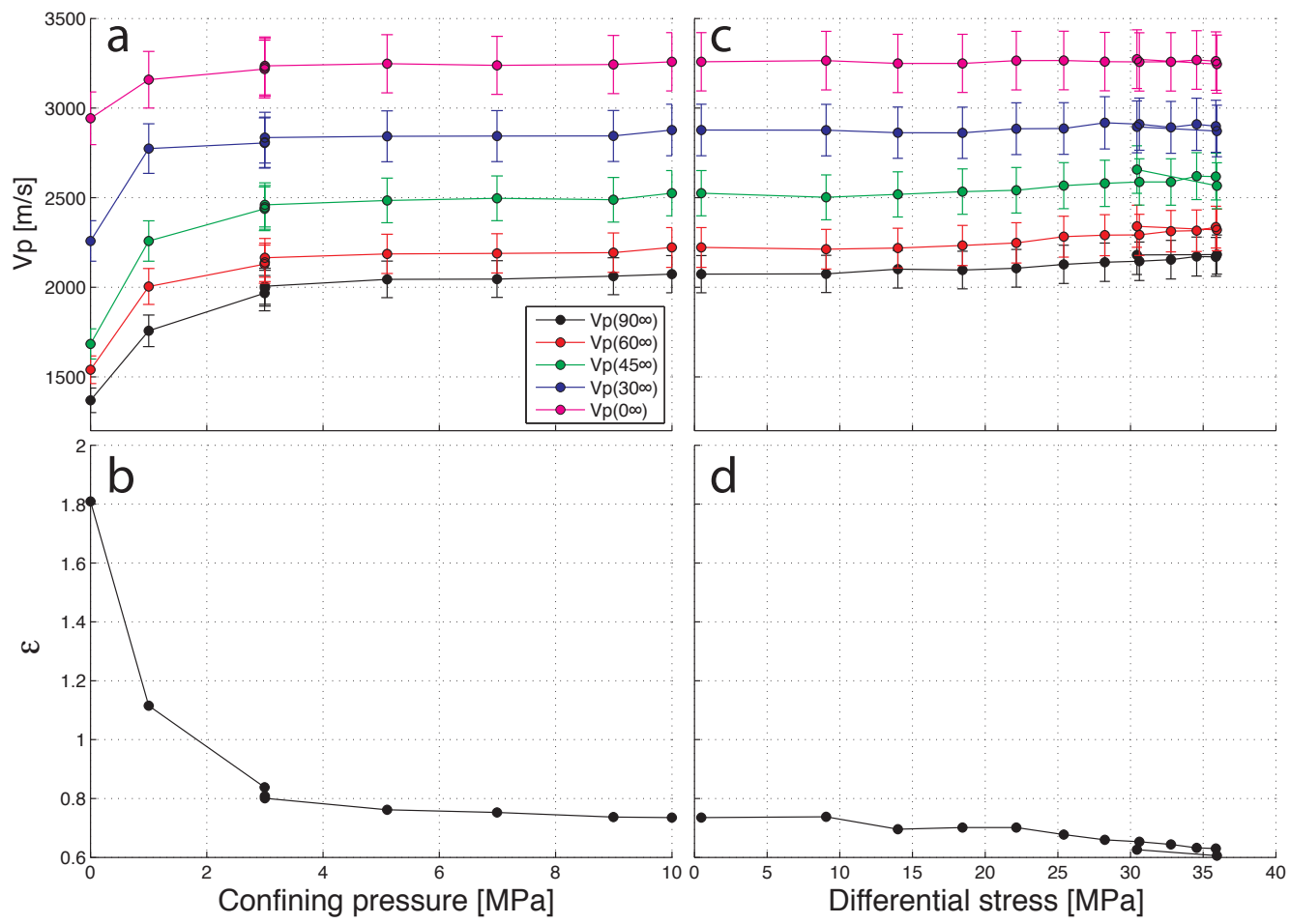

Figure 7: Evolution of P-wave group (ray) velocity and anisotropy (Thomsen's $\varepsilon$ parameter) with confining pressure and deviatoric loading. P-wave velocity data are indicated with a $10 \%$ error bar $(+/-5 \%)$. The magnitude of the $\mathrm{P}$-wave velocity as a function of the 49

propagation direction with respect to the bedding illustrates the elastic anisotropy of the shale. This anisotropy decreases significantly with increasing confining pressure, and is virtually not sensitive to the axial stress, at least until the strain localises in a shear fault and the specimen fails. The non-linear variation of the $\mathrm{P}$-wave velocity with confining pressure up to about $4 \mathrm{MPa}$ suggests the existence of damage in the shale specimen at 

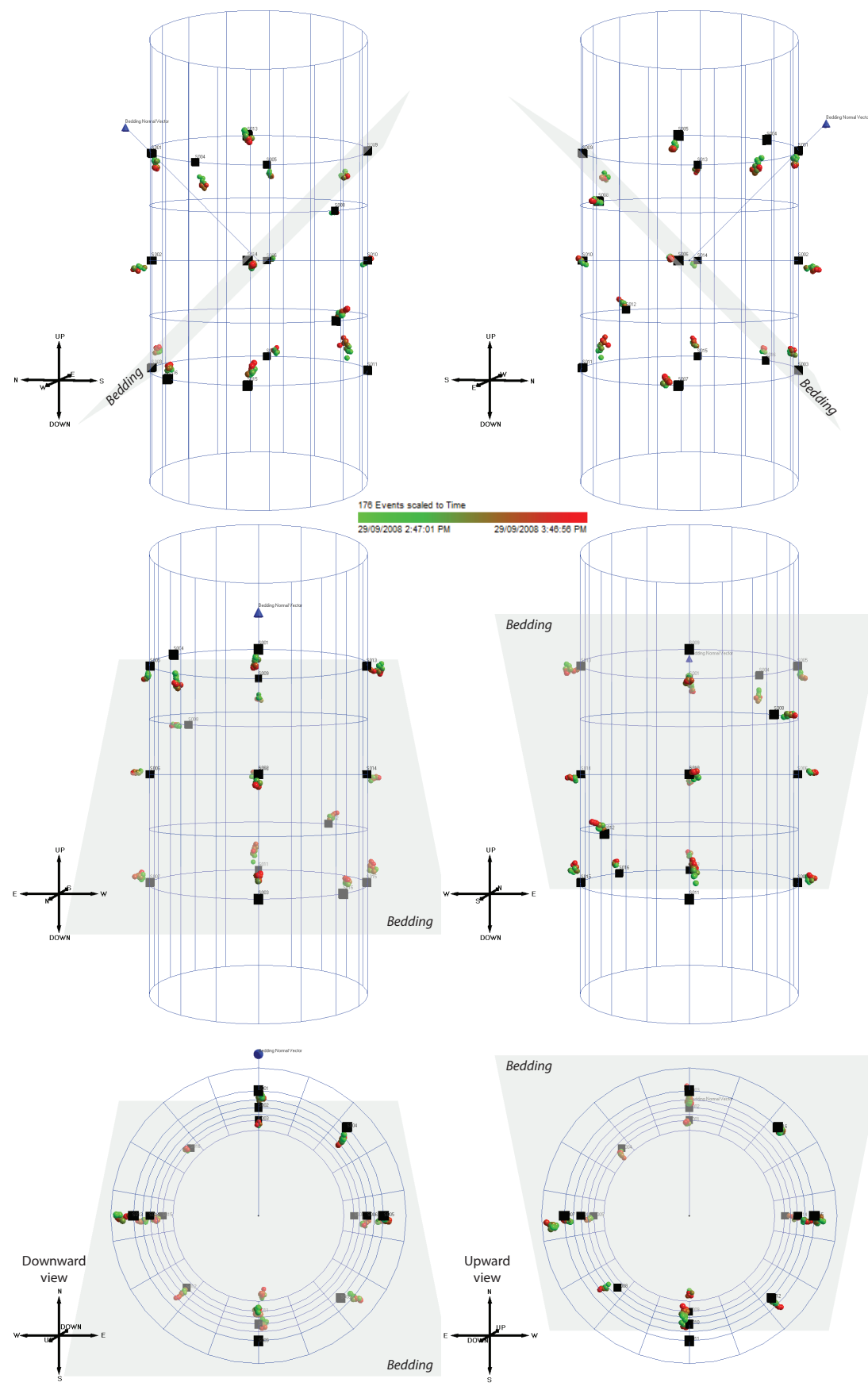

Figure 8: Spatial and temporal location of the ultrasonic sources shot during the velocity surveys. The squares represent the nominal position of the centre of the ultrasonic sensors; the spheres represent the location of the sources obtained by inversion using the selected velocity model. 

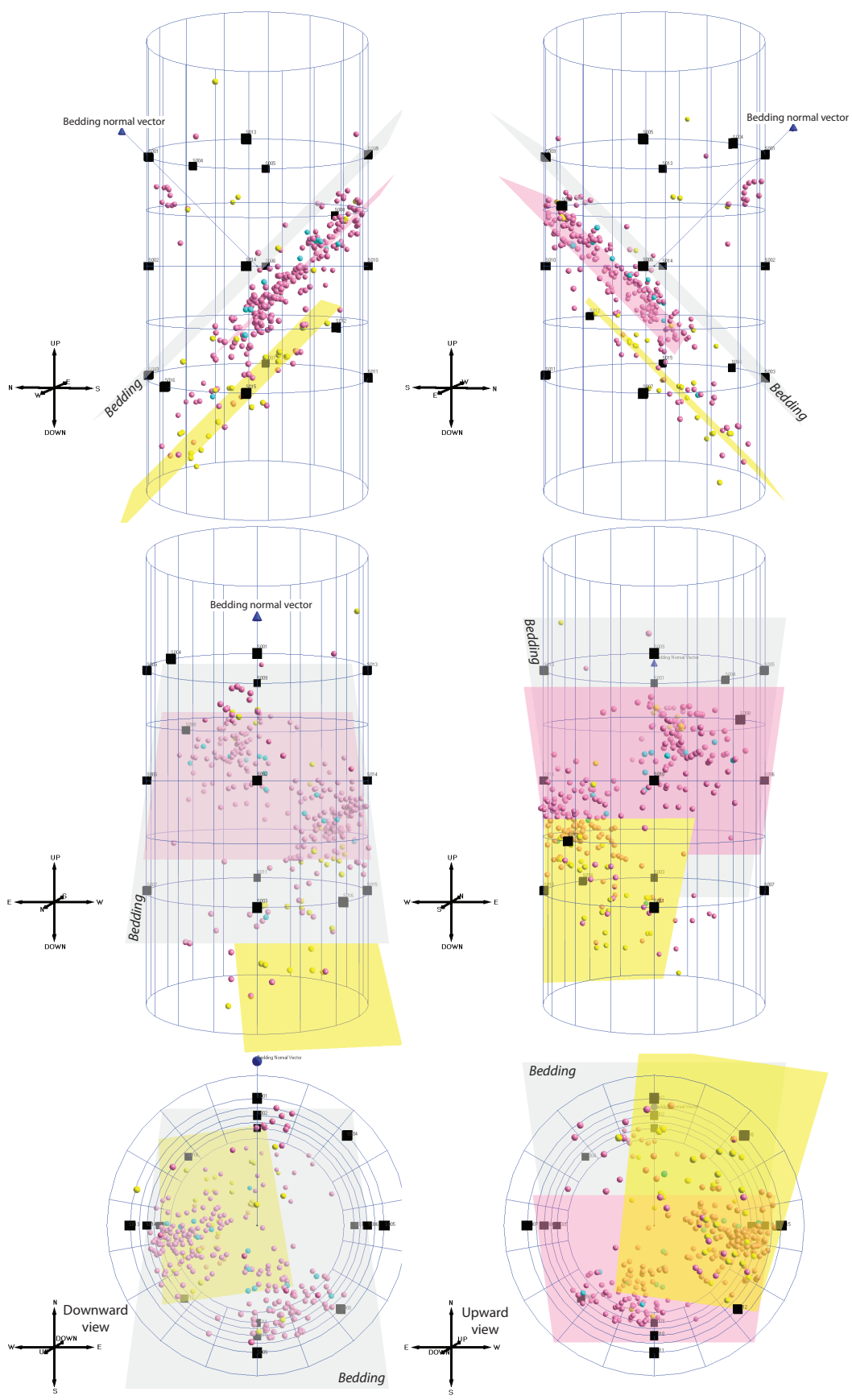

Figure 9: Spatial and temporal location of the micro-seismic events recorded during the three phases of the deviatoric loading: in yellow for Phase 1; in blue for Phase 2; and in pink for Phase 3. The micro-seismic activity suggests the existence of two overlapping shear fault planes. Part of the micro-seismic activity locates in the overlap volume between these two planes. A feature similar to relay ramps observed in large scale structural geology. 

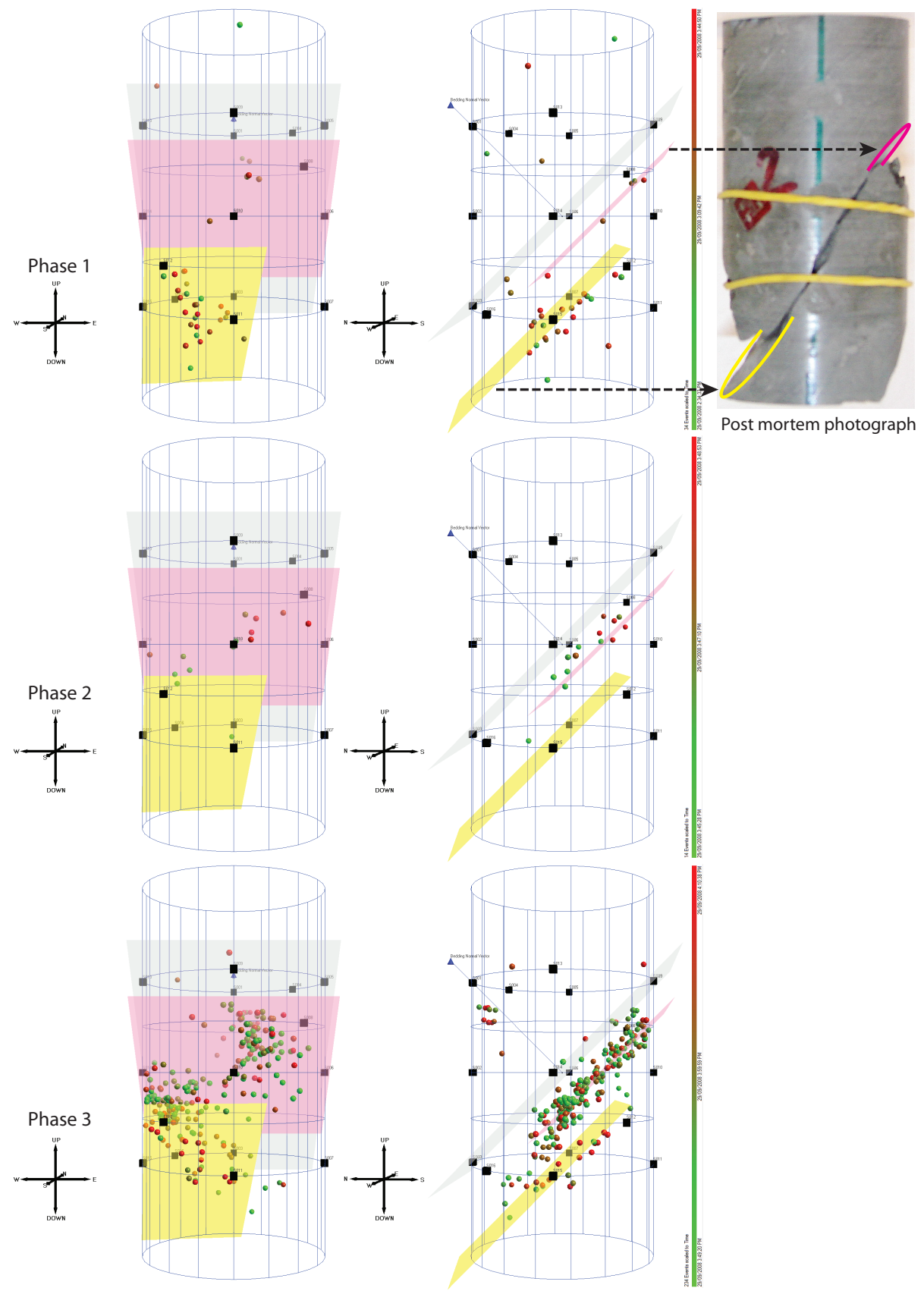

Figure 10: Spatial and temporal location of the recorded MSEs separated into the three phases of the experiment. For each phase, the color of each event is scaled to its time of occurence, i.e., first events of the phase in green and last events in red. These results suggest that the lower shear fault (yellow plane) is most active (accommodates most of the imposed axial displacement) at the early stages after strain localisation (Phase 1). During Phase 2, a transition of the micro-seismic activity is observed from the lower shear fault toward the upper shear fault (pink plane). During Phase 3 most of the imposed axial displacement is accommodated by the upper shear fault although few events are still 


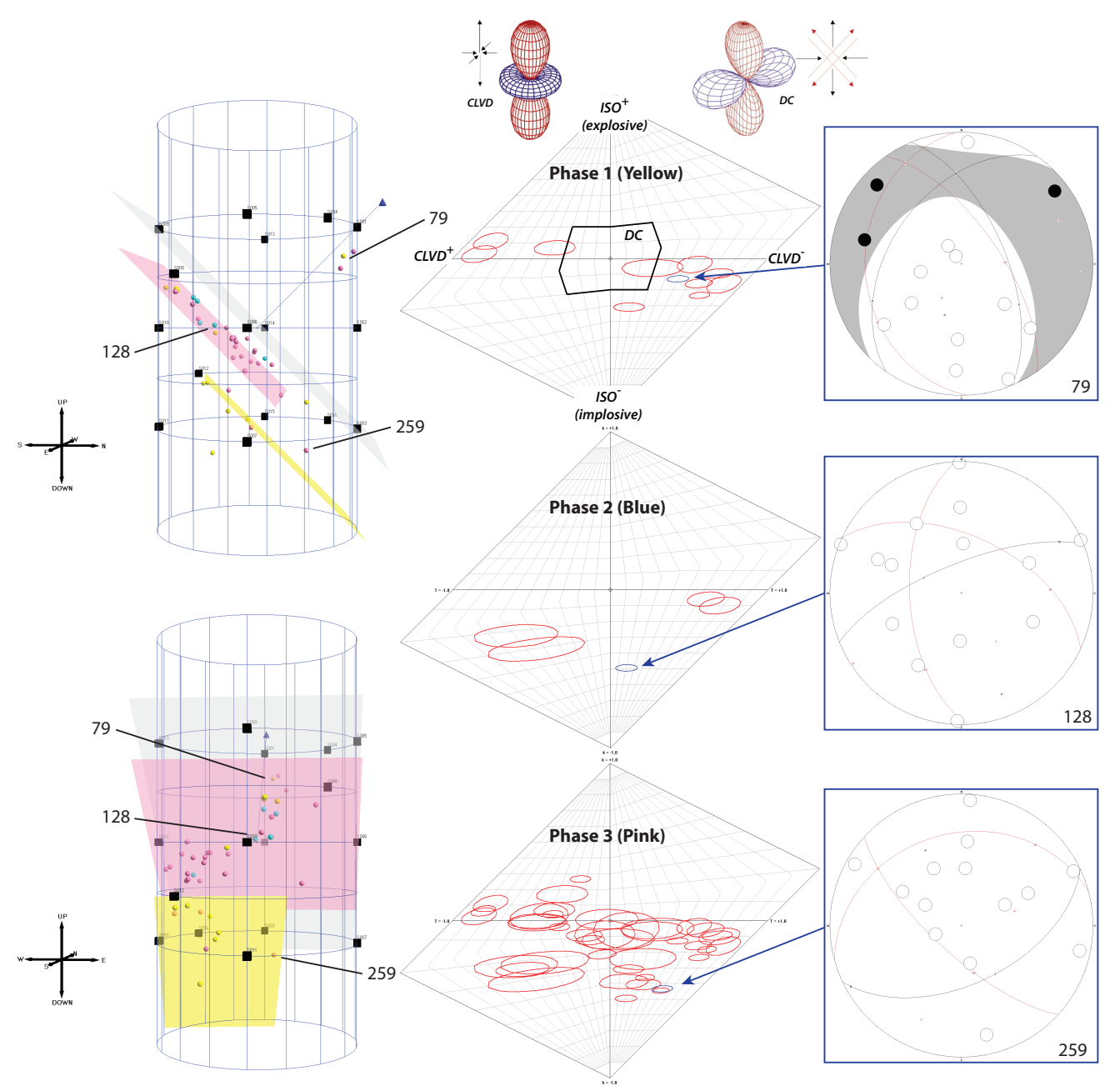

Figure 11: Spatial location, T-k decomposition in Hudson's diagram [23], and moment tensor solution of the MSE with largest magnitude in each of the three phases of the experiment: MSE \#79 in Phase 1, MSE \#128 in Phase 2 and MSE \#259 in Phase 3. 

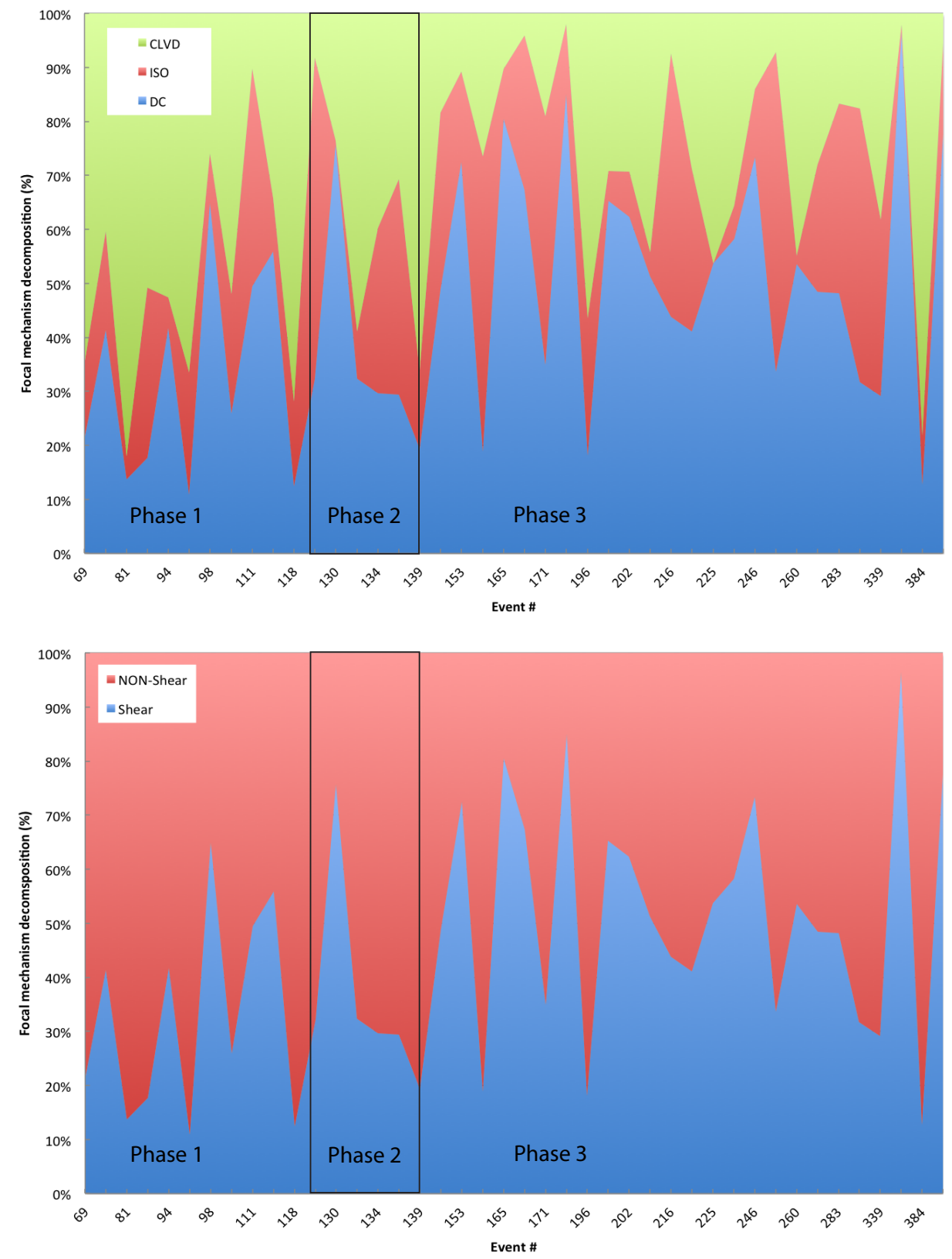

Figure 12: Results of the moment tensor decomposition of the selected high quality MSEs. The top plot shows the detailed decomposition into DC, CLVD and ISO MSEs; the lower plot shows the simpler decomposition into shear and non-shear MSEs (see main text for details). 54 

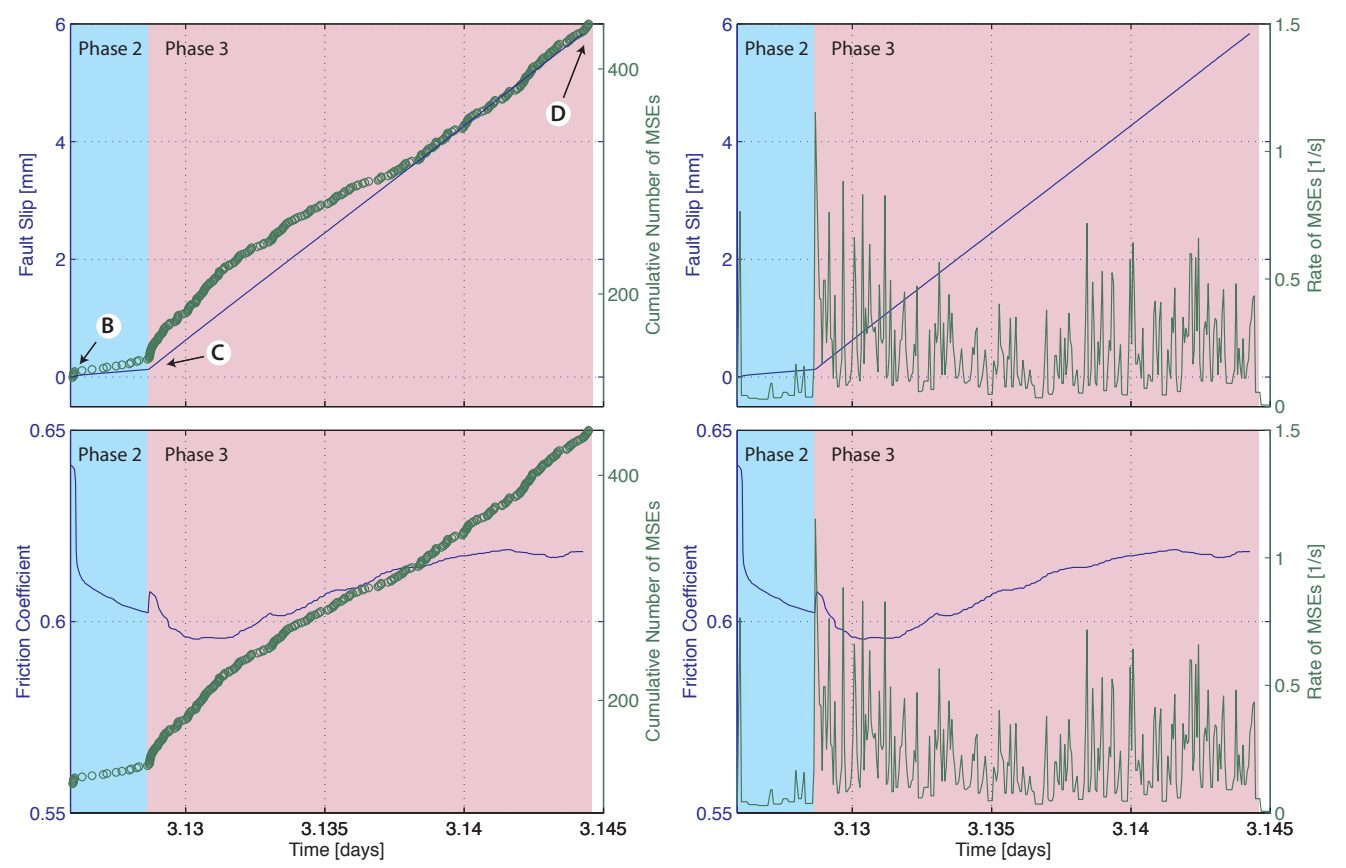

Figure 13: Fault frictional behaviour and MS activity during Phases 2 and 3. The fault slip is calculated from the measured post-failure axial displacement and the orientation of the fault plane determined post mortem to be approximately at $45^{\circ}$ to the specimen's axis. 